\title{
Development
}

\section{NGF-Dependent and BDNF-Dependent DRG Sensory Neurons Deploy Distinct Degenerative Signaling Mechanisms}

\author{
Andrés de León, ${ }^{1,2}$ - Julien Gibon, ${ }^{2}$ and Philip A. Barker ${ }^{2}$
}

https://doi.org/10.1523/ENEURO.0277-20.2020

${ }^{1}$ Department of Neurology and Neurosurgery, Montreal Neurological Institute, McGill University, Montreal, Quebec H3A 2B4, Canada and 'Department of Biology, University of British Columbia Okanagan, Kelowna, British Columbia V1V 1V7, Canada

\begin{abstract}
The nerve growth factor (NGF) and brain-derived neurotrophic factor (BDNF) are trophic factors required by distinct population of sensory neurons during development of the nervous system. Neurons that fail to receive appropriate trophic support are lost during this period of naturally occurring cell death. In the last decade, our understanding of the signaling pathways regulating neuronal death following NGF deprivation has advanced substantially. However, the signaling mechanisms promoting BDNF deprivation-induced sensory neuron degeneration are largely unknown. Using a well-established in vitro culture model of dorsal root ganglion (DRG), we have examined degeneration mechanisms triggered on BDNF withdrawal in sensory neurons. Our results indicate differences and similarities between the molecular signaling pathways behind NGF and BDNF deprivation-induced death. For instance, we observed that the inhibition of Trk receptors (K252a), PKC (Gö6976), protein translation (cycloheximide; CHX), or caspases (zVAD-fmk) provides protection from NGF deprivationinduced death but not from degeneration evoked by BDNF-withdrawal. Interestingly, degeneration of BDNFdependent sensory neurons requires BAX and appears to rely on reactive oxygen species (ROS) generation rather than caspases to induce degeneration. These results highlight the complexity and divergence of mechanisms regulating developmental sensory neuron death.
\end{abstract}

Key words: axons; BAX; BDNF; degeneration; dorsal root ganglion; NGF

\section{Significance Statement}

The elimination of neuronal cells generated in excess during embryonic stages characterizes the maturation of the nervous system. Here, we address the developmental cell death mechanisms of brain-derived neurotrophic factor (BDNF)-dependent dorsal root ganglion (DRG) neurons in vitro, comparing and contrast them with those deployed in NGF-dependent sensory neurons. We observe several important differences between the molecular signaling pathways behind nerve growth factor (NGF) and BDNF deprivation-induced death. Significantly, degeneration of BDNF-dependent sensory neurons requires BAX but not caspase activation, instead reactive oxygen species (ROS) generation appears to play a key role in degeneration. This work highlights the complexity of cell death mechanisms in distinct embryonic sensory neuron populations.

\section{Introduction}

The developing nervous system undergoes a period of neuronal cell death during embryogenesis (Patel et al.,

\footnotetext{
Received June 19, 2020; accepted December 7, 2020; First published December 28, 2020.

The authors declare no competing financial interests.
}

2000; Buss et al., 2006; Schuldiner and Yaron, 2015). In this period, neurons that fail to receive trophic support die by apoptosis (Burek and Oppenheim, 1996), a type of cell

Author contributions: A.d.L., J.G., and P.A.B. designed research; A.d.L. performed research; A.d.L., J.G., and P.A.B. analyzed data; A.d.L., J.G., and P.A.B. wrote the paper. 
death also commonly observed in neurodegenerative diseases (Kirkland and Franklin, 2003; Fischer and Glass, 2007; Saxena and Caroni, 2007; Vickers et al., 2009; Tait and Green, 2010; Kanaan et al., 2013). The mammalian peripheral nervous system (PNS) offers a well-characterized context to study developmental neuronal apoptosis. Diverse sub-types of sympathetic and sensory neurons develop, compete, survive, or die based on their capacity to bind enough trophic support from their target tissue (Barde, 1989; Saxena and Caroni, 2007).

Neurotrophins are crucial regulators of survival during the development of the nervous system. Alterations of their levels induce dramatic changes of innervation in the adult PNS (Levi-Montalcini and Booker, 1960; Ernfors et al., 1994a,b; Tessarollo et al., 1997). In mammals, the neurotrophin family is composed of the nerve growth factor (NGF), brain-derived neurotrophic factor (BDNF), neurotrophin-3 (NT3), and neurotrophin-4/5 (NT4/5). With equal low affinity and no selectivity, each neurotrophins can bind to the pan-neurotrophin receptor p75 (p75NTR), and with high affinity to the tropomyosin-related kinase (Trk) receptor family: with NGF binding to TrkA, BDNF and NT4/5 to TrkB and NT3 to TrkC. Sympathetic and sensory neurons can be classified based on their expression profile of Trk receptors and their requirement for neurotrophins. Most sympathetic and sensory neurons depend on the NGF-TrkA signaling pathway during development (Kirstein and Fariñas, 2002; Glebova and Ginty, 2005; Lallemend and Ernfors, 2012). In vitro models using cultured sympathetic and dorsal root ganglia (DRGs) neurons that are maintained and then withdrawn from NGF have provided many key insights into the cell autonomous mechanisms that drive developmental neuronal cell death (Unsain et al., 2013, 2014; Geden et al., 2019). Recent work has shown that embryonic sensory neurons deprived of NGF results in PKC activation, ROS production, and TRPV1 activation which in turn induces a large increase in axoplasmic $\mathrm{Ca}^{2+}$ required for degeneration (Johnstone et al., 2018, 2019). To date, almost all studies have focused on NGF-sensitive peripheral neurons and mechanisms driving developmental neuronal death in other peripheral neuronal populations remains essentially unknown. In the present study, we asked whether the degenerative cascade initiated by NGF withdrawal could be extrapolated to population of neurons dependent on other neurotrophins, with a particular focus on the degenerative processes affecting BDNF-sensitive neurons.

Here, we show that NGF-dependent and BDNF-dependent DRG neurons undergo axonal blebbing, reduced axonal area, increased extracellular phosphatidylserine, and rise in intracellular $\mathrm{Ca}^{2+}$ when withdrawn from trophic

This work was supported by the Canadian Institute of Health Research Grant MOP137057 (to P.A.B.).

Correspondence should be addressed to Philip A. Barker at philip.barker@ ubc.ca.

https://doi.org/10.1523/ENEURO.0277-20.2020

Copyright @ 2021 de León et al.

This is an open-access article distributed under the terms of the Creative Commons Attribution 4.0 International license, which permits unrestricted use, distribution and reproduction in any medium provided that the original work is properly attributed. support. Further, degeneration of both classes of neurons require the proapoptotic protein BAX. However, unlike NGF-sensitive neurons, degeneration of BDNF-dependent deprivation does not require Trk activity, PKC activity or caspase activity and instead requires reactive oxygen species (ROS). Together, these results highlight the complexity and divergence of the mechanisms underlying trophic factor deprivation-induced neuronal cell death during development in the PNS.

\section{Materials and Methods}

\section{Mouse strains}

CD1 mice were purchased from Charles River Laboratories. The previously described p75NTR knockout mice (Lee et al., 1992) and BAX knock-out mice (Knudson et al., 1995) were maintained in a C57BI6 strain background. Animal procedures and experiments were approved by the University of British Columbia animal care committee and the Canadian Council of Animal Care. Efforts were made to reduce animal handling and use.

\section{Culturing and trophic factor deprivation of DRG explants}

DRGs were dissected from embryonic day (E)13.5 mouse embryos and seeded in 12-well plastic (Grenier) or four-well glass-bottom dishes (CellVis) sequentially coated with $1 \mathrm{mg} /$ $\mathrm{ml}$ poly-D-lysine (Sigma-Aldrich), $10 \mu \mathrm{g} / \mathrm{ml}$ laminin-entactin complex (Corning), and $0.1 \mathrm{mg} / \mathrm{ml}$ PurCol bovine collagen (Advanced Biomatrix). Explants were grown in phenolred Neurobasal media (Invitrogen) supplemented with 2\% B27 serum-free supplement (Invitrogen), 1\% L-glutamine (Wisent), 1\% penicillin/streptomycin (Wisent), $10 \mu \mathrm{m}$ 5-fluoro-2'-deoxyuridine (FDU; Sigma-Aldrich), and $12.5 \mathrm{ng} / \mathrm{ml}$ NGF (CedarLane) or $37.5 \mathrm{ng} / \mathrm{ml}$ BDNF (CedarLane) at $37^{\circ} \mathrm{C}, 5 \% \mathrm{CO}_{2}$. Deprivation of neurotrophic support was accomplished using $2.0 \mu \mathrm{g} / \mathrm{ml}$ of function blocking antibodies against NGF (homemade rabbit polyclonal antibody raised against 2.5s NGF; Acheson et al., 1991) or BDNF (mouse monoclonal, DSHB \#9-b) in complete fresh media without neurotrophic supplementation.

\section{$\beta$ III-tubulin immunocytochemistry, imaging and quantification of axon degeneration}

DRG explants were fixed in 4\% paraformaldehyde solution in PBS for $15 \mathrm{~min}$, washed once in PBS and blocked in $5 \%$ milk in Tris-borate buffer and $0.3 \%$ Triton X-100 for $1 \mathrm{~h}$ at room temperature (RT). Explants were incubated overnight at $4{ }^{\circ} \mathrm{C}$ with mouse monoclonal antibody against $\beta$ III-tubulin (Millipore, MAB5564) diluted 1:10,000 in blocking solution. DRGs were washed twice in PBS and then incubated with goat anti-mouse conjugated to Alexa Fluor 488 (Jackson ImmunoResearch, 115-545-003) diluted 1:5000 in blocking solution for a minimum of $3 \mathrm{~h}$ at RT. Explants were imaged using a Zeiss ObserverZ.1 inverted epifluorescence microscope with an automated motorized stage ( $5 \times$ magnification with tilling). From a stitched master image of the plate generated by Zen 2 
software (Zeiss), quarter DRG fields were cropped to generate a set of images for analysis using the $\mathrm{R}$ script program Axoquant 2.0 (Johnstone et al., 2018). Final measurements were plotted as the mean axonal area of DRGs from three embryos. Increments of $500 \mu \mathrm{m}$ were used for statistical analysis (normalized to same increments in control condition).

\section{Assessment of DRG explant survival with live Calcein- AM staining \\ DRG explants were treated with $1 \mu \mathrm{g} / \mathrm{ml}$ Calcein-AM} (AAT Bioquest) in neurobasal media for $1 \mathrm{~h}$ at $37^{\circ} \mathrm{C}$ then switched to clear HBSS-based complete media supplemented with HEPES to maintain physiological $\mathrm{pH}$. Explants were tiled-imaged using a Zeiss ObserverZ.1 inverted epifluorescence microscope with an automated motorized stage. From a stitched master image of the plate generated by the Zen 2 software, cell bodies and Schwann cells were cropped out and a binary mask image of each explants was created using NIH ImageJ software. Explant area and mean pixel intensity value corrected by the background signal were quantified to provide either the area of Calcein-AM-stained axons over a specified threshold or Calcein-AM fluorescence intensity per unit of area. DRG explants from the same embryo were pooled and averaged to generate the mean value for each embryo. Measurements were normalized relative to NGF or BDNF wild-type conditions.

\section{Annexin-V staining, imaging, and quantification}

DRG explants seeded on glass bottom dishes (CellVis) were incubated with $1 \mu \mathrm{g} / \mathrm{ml}$ Annexin-V (AAT Bioquest) in annexin-V buffer (10 mM HEPES/NaOH, pH7.4, $140 \mathrm{~mm}$ $\mathrm{NaCl}$, and $2.5 \mathrm{mM} \mathrm{CaCl}_{2}$ ) for $15 \mathrm{~min}$ at RT. DRGs were washed and tiled-imaged in the annexin-V buffer using a Zeiss Observer Z.1 inverted epifluorescence microscope (40 $\times$ magnification). Stitched master images of each explant generated by Zen 2 software were cropped to eliminate soma and Schwann-cell area and axonal annexin-V area was measured using a binary mask over an established threshold for all explants. DRG explants from the same embryo were pooled and averaged to generate the mean value for each embryo. Measurements were normalized relative to NGF or BDNF controls.

\section{$\mathrm{Ca}^{2+}$ imaging with Fluo-4 and quantification}

DRG explants were seeded on glass bottom dishes (CellVis) and treated with $5 \mu \mathrm{m}$ Fluo-4 AM (Invitrogen) in neurobasal media for $15 \mathrm{~min}$ at $37^{\circ} \mathrm{C}$, washed with HBSS and switched to clear HBSS-based complete media supplemented with HEPES (final concentration $20 \mathrm{~mm}$ ) to maintain its physiological $\mathrm{pH}$. Explants were tiled-imaged using a Zeiss ObserverZ.1 inverted epifluorescence microscope with an automated motorized stage at $40 \times$ magnification. Employing NIH ImageJ software, stitched master images of each explant were cropped to eliminated soma and Schwann-cell area. From there, a binary mask image of remaining axons was created to measure area and mean pixel intensity corrected by background signal. After calculating the intensity per unit of axonal area, DRG explants from the same embryo were pooled and averaged to generate the mean value per embryo. Measurements were normalized and expressed as foldchange from NGF or BDNF controls.

\section{Immunoblotting}

For SDS-PAGE and Western blot analysis, a total of 25 DRG explants per well were seeded in 12-well plastic plates (Grenier). For protein harvesting, cultures were washed with PBS, and DRGs were scraped into $90 \mu \mathrm{l}$ of sample buffer (4\% SDS, 20\% glycerol, 10\% 2-mercaptoethanol, $0.004 \%$ bromophenol blue, and $0.125 \mathrm{~m}$ Tris$\mathrm{HCl}, \mathrm{pH} \sim 6.8$ ). Samples were boiled for $5 \mathrm{~min}$, centrifuged, and stored at $-80^{\circ} \mathrm{C}$ for later analysis. Antibodies used for immunoblotting were: anti- $\beta$ III-tubulin (Millipore MAB5564, 1:10,000), anti-neurofilament $M$ (Millipore $A B 1987,1: 1000)$, anti-caspase-3 (NEB 9662, 1:1000), anti-TrkA (Millipore 06-574, 1:1000), anti-TrkB (Millipore 07-225, 1:1000), anti-TrkC (Millipore 07-226, 1:1000), and the previously described anti-p75NTR (Barker and Shooter, 1994).

\section{Pharmacological PKC, Trk, caspase, autophagy, translation, and necroptosis inhibitors}

Stocks of PKC inhibitor Gö6976 (10 mm, Tocris 2253), Trk receptor inhibitor K252a (200 $\mu \mathrm{M}$, Calbiochem \#420298), pan-caspase inhibitors Boc-D-fmk (10 mm, Abcam ab142036), zVAD-fmk (20 mm, R\&D Systems FMK001), and necroptosis inhibitor necrostatin-1 (NEC-1; 100 $\mathrm{mm}$, Sigma-Aldrich N9037) were prepared in dimethylsulfoxide (DMSO) and used at 1:1000 dilution (final concentration of DMSO below $0.1 \%)$. The translation inhibitor cycloheximide (CHX; R\&D Systems 0970/100) was dissolved at $1.0 \mathrm{~g} / \mathrm{l}$ in water and used at 1:1000. Autophagy inhibitor 3-methyladenine (3-MA; SigmaAldrich M9281) was dissolved at $10 \mathrm{~mm}$ in phenol-red neurobasal media. Drugs were applied at the same time that the trophic factor withdrawal was initiated.

\section{EGTA, NAC, and NAD + preparation}

EGTA (AlfaAesar A16086, final concentration $5 \mathrm{~mm}$ ), $N$ acetylcysteine (NAC; Sigma, A9165, final concentration $20 \mathrm{~mm}$ ), or nicotinamide adenine dinucleotide (NAD+, Sigma-Aldrich, N7004, final concentration $5 \mathrm{~mm}$ ) was dissolved in Neurobasal media, pH adjusted to 7.4, and filtered by $0.22 \mu \mathrm{m}$ for final treatment of DRG explants. After $48 \mathrm{~h}$ of growth in NGF or BDNF, cultures were either maintained with trophic support or deprived of it, in the absence or presence of each specific compound for the entire deprivation period.

\section{Experimental design and statistical analysis}

Data were plotted and analyzed using Prism 6 (GraphPad). All data were presented as mean \pm SEM. The number of embryos $n$ in each experiment or condition is described in each figure legend. Mann-Whitney test (unpaired, two-tailed) was used for two-group experiments comparisons. Two-way ANOVA with Bonferroni's post 
A

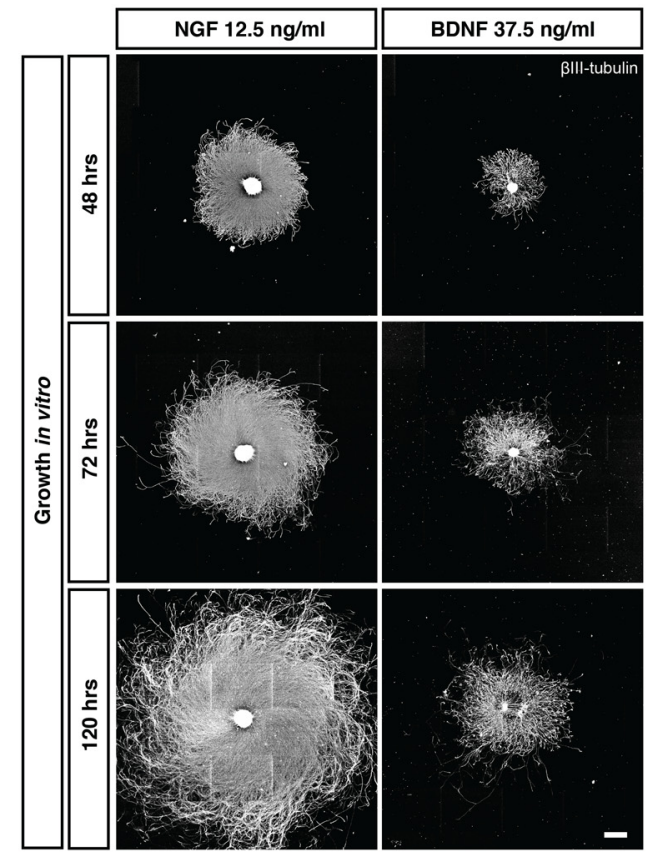

B
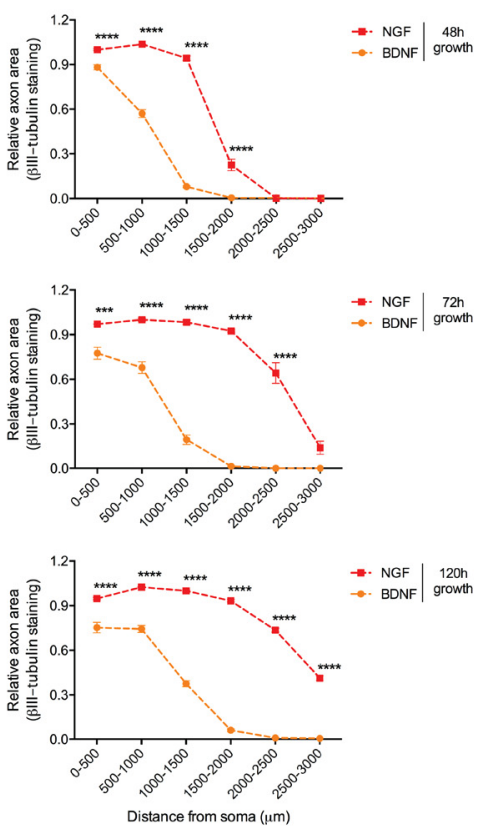

C

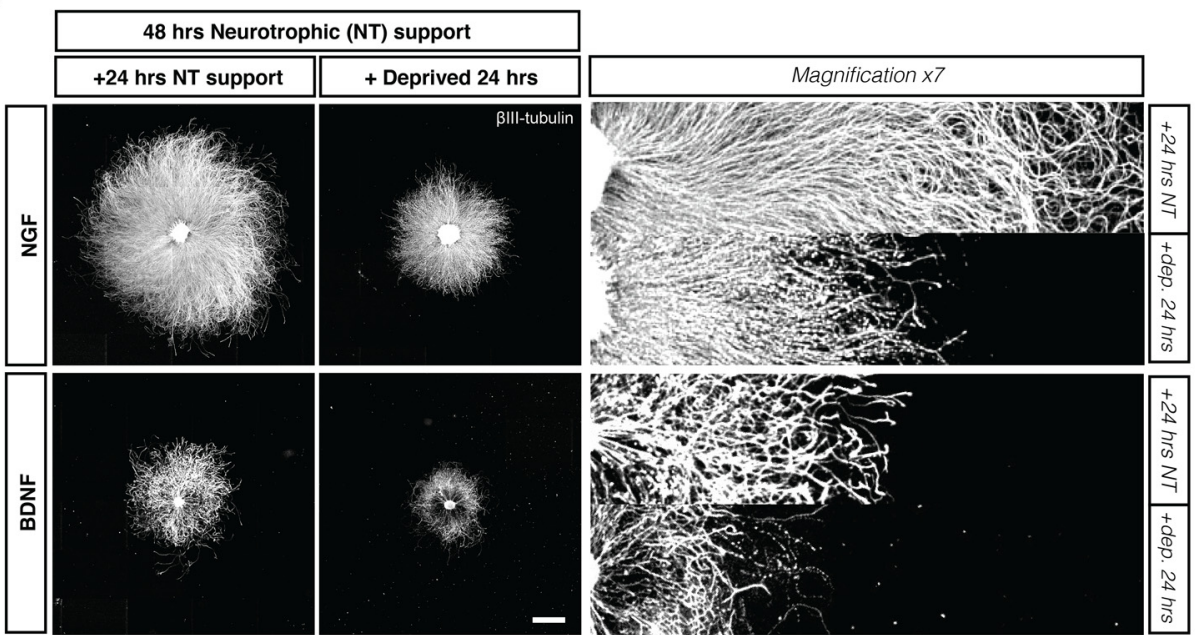

D

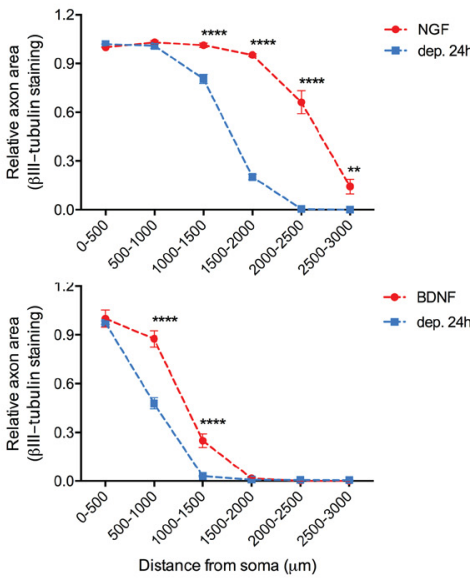

Figure 1. Comparative growth of NGF-dependent and BDNF-dependent DRG sensory neurons and their degeneration induced by trophic factor withdrawal. $\boldsymbol{A}, \beta$ III-tubulin staining of embryonic mice DRG explants cultured in the presence of NGF (12.5 $\mathrm{ng} / \mathrm{ml}$ ) or BDNF $(37.5 \mathrm{ng} / \mathrm{ml})$ for 48,72 , or $120 \mathrm{~h}$. Scale bar: $1000 \mu \mathrm{m}$. B, Quantification of axonal area as a function of the distance from the soma using Axoquant 2.0 (Johnstone et al., 2018) and plotted in 500- $\mu \mathrm{m}$ bins. The difference between the relative axonal area between NGF-dependent and BDNF-dependent DRG growth at different time points were analyzed by two-factor ANOVA and Bonferroni's post hoc comparison and plotted with mean and SEM ( $n=3$ embryos for each condition; data shown are representative of three independent experiments); ${ }^{\star}$ NGF versus BDNF; ${ }^{\star * \star} p<0.001,{ }^{* \star * \star} p<0.0001$. $\boldsymbol{C}$, DRG explants cultured in the presence of NGF or BDNF for $48 \mathrm{~h}$ and then either maintained with trophic support or deprived with a function blocking anti-NGF $(2 \mu \mathrm{g} / \mathrm{ml})$ or anti-BDNF $(2 \mu \mathrm{g} / \mathrm{ml})$ for the following $24 \mathrm{~h}$, before fixation and immunostaining with $\beta$ Ill-tubulin. Scale bar: $1000 \mu \mathrm{m}$. $\boldsymbol{D}$, NGF and BDNF deprivation for $24 \mathrm{~h}$ results in a significant loss of $\beta$ Ill-tubulin-stained axons expressed as axonal area relative to $0-500 \mu \mathrm{m}$ NGF or BDNF controls; analyzed by two-factor ANOVA and Bonferroni's post hoc comparison and plotted with mean and SEM; ${ }^{\star *} p<0.01,{ }^{* \star *} p<0.001,{ }^{* \star \star *} p<0.0001$.

hoc test or Tukey's post hoc test was used to analyze differences in multiple groups. In all graphs, non-significant $(p>0.05)$ : ns, ${ }^{*}$ (or other symbols) $p<0.05,{ }^{\star *} p<0.01$, ${ }^{* * *} p<0.001$, and ${ }^{* * *} p<0.0001$.

\section{Results}

The apoptotic machinery involved in NGF deprivationinduced axonal degeneration in DRG neurons is well characterized (Geden et al., 2019). However, our knowledge of 
A

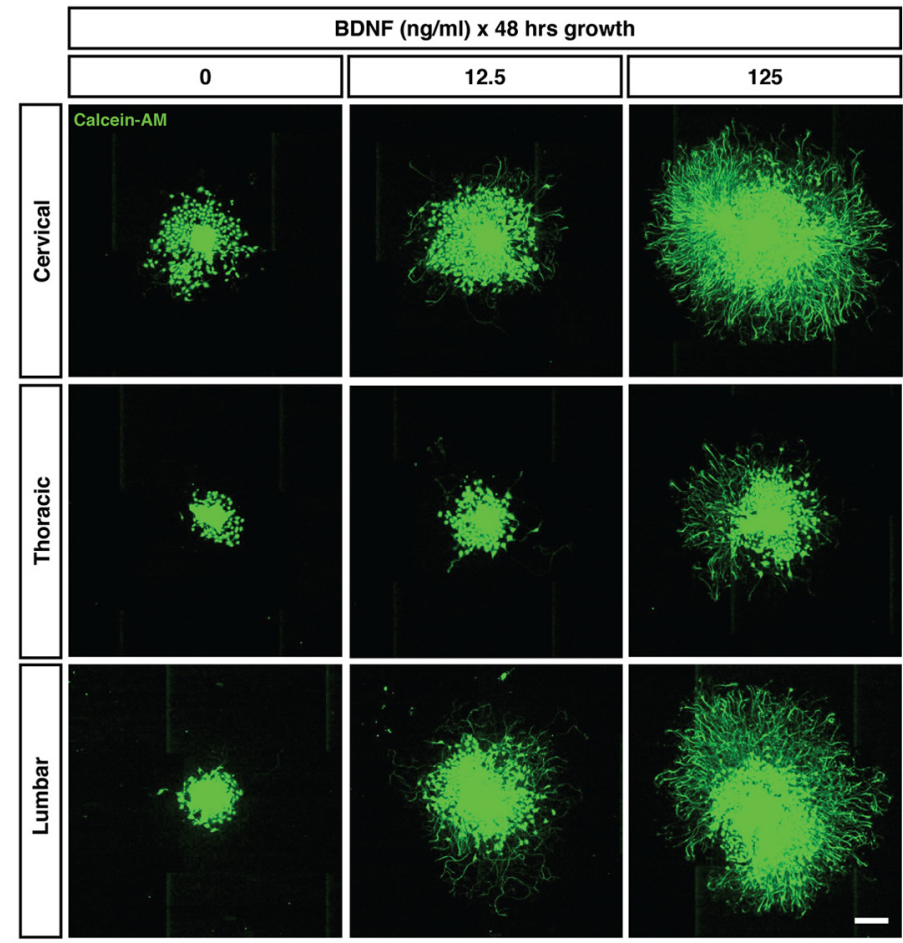

B

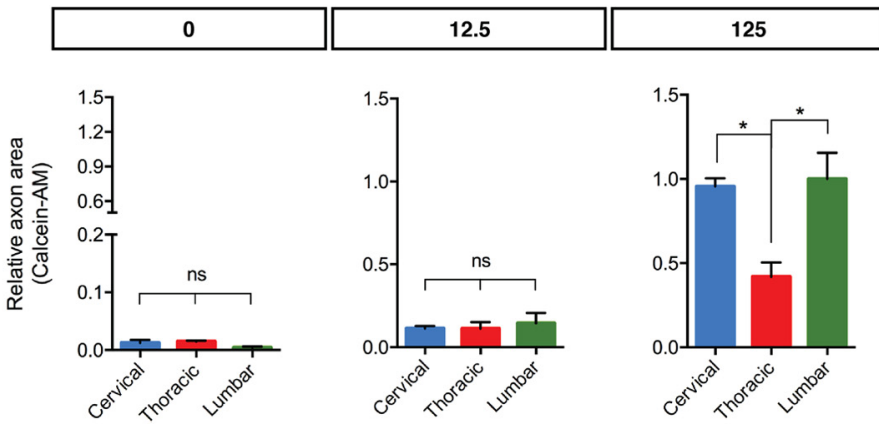

Figure 2. Axon growth of BDNF-dependent DRGs from the cervical, the thoracic or the lumbar region of the spinal cord with several concentration of BDNF. A, Calcein-AM-stained DRGs from cervical, thoracic or lumbar spinal cord segments of E13.5 mice embryos were grown for $48 \mathrm{~h}$ in 0, 12.5, or $125 \mathrm{ng} / \mathrm{ml}$ of BDNF. Scale bar: $500 \mu \mathrm{m}$. B, Quantification of Calcein-AM-stained axonal area relative to Calcein-AM-stained axonal area of lumbar DRGs at $125 \mathrm{ng} / \mathrm{ml}$ analyzed by one-factor ANOVA and Tukey's post hoc comparison and plotted with mean and SEM $(n=3$ embryos for each condition; data shown are representative of three independent experiments). ns: non-significant; * $p<0.05$.

axonal degeneration induced by BDNF deprivation is rudimentary. To begin to address this, we characterized BDNF withdrawal-induced axon degeneration in DRG neurons generated from E13.5 mice embryos. Figure $1 \mathrm{~A}$ shows that E13.5 DRGs cultured in the presence of BDNF survived and developed neurites (quantified in Fig. 1B). The extent and density of neurites was maximal at a BDNF concentration of $125 \mathrm{ng} / \mathrm{ml}$ (Fig. $2 A$ ), but even at this concentration, processes were significantly less dense and shorter than within parallel DRGs cultured in NGF (data not shown). It was also noted that DRGs derived from the lumbar and cervical parts of the spinal cord extended more exuberant processes in response to BDNF than DRGs derived from the thoracic region (Fig. $2 B$ ). For subsequent experiments, cervical DRG neurons were routinely cultured using $37.5 \mathrm{ng} / \mathrm{ml}$ of BDNF or $12.5 \mathrm{ng} / \mathrm{ml}$ of NGF. For BDNF-deprivation studies, cells were grown in BDNF for $48 \mathrm{~h}$ and then switched to BDNFfree media supplemented with an anti-BDNF monoclonal antibody for $24 \mathrm{~h}$. Axons maintained and then deprived of BDNF in this manner showed morphologic signs of degeneration and blebbing (Fig. 1C, higher magnification, quantified in $D$ ).

Cell biological and biochemical indications of BDNFwithdrawal induced axonal degeneration were also established. DRG axons that were maintained and then deprived of either NGF or BDNF show a significant increase of extracellular phosphatidylserine, determined using Annexin- $V$ staining, and a drastic decrease of viable axons, determined using Calcein-AM (Fig. 3A, quantified 
A

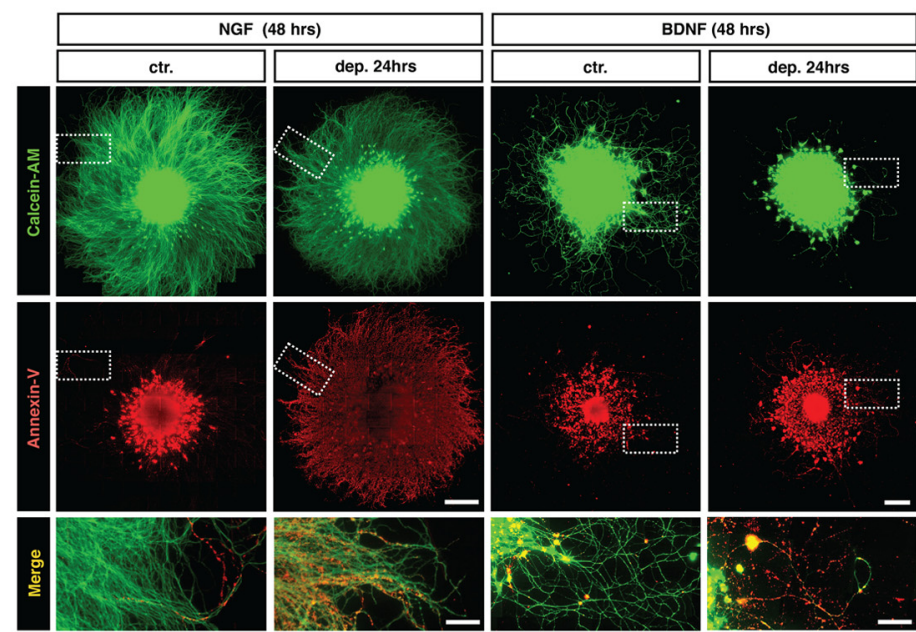

B
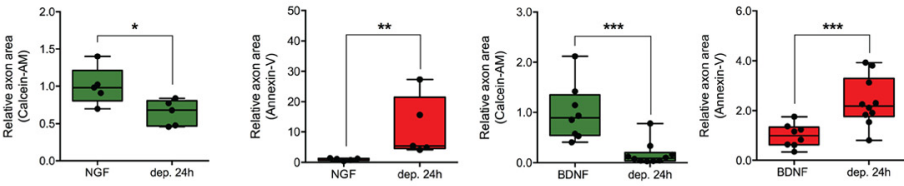

C

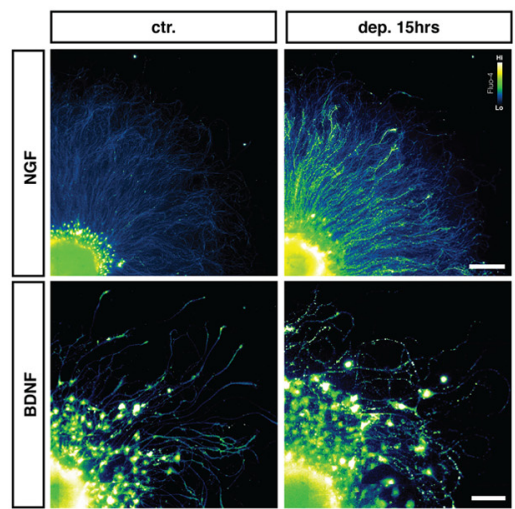

D
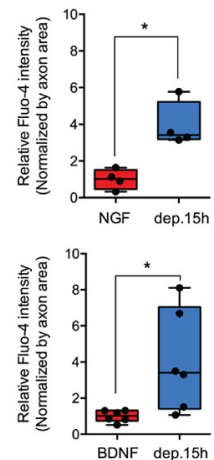

Figure 3. DRG sensory neurons undergoing BDNF deprivation display increased extracellular phosphatidylserine and increased axoplasmic $\mathrm{Ca}^{2+} . \boldsymbol{A}$, DRG explants cultured in the presence of NGF or BDNF for $48 \mathrm{~h}$ and then either maintained with trophic support (ctr) or deprived with an antibody against NGF or BDNF for the following $24 \mathrm{~h}$ (dep) were co-stained with Calcein-AM (green) and Annexin- $V$ (red) to measure the area of healthy axons versus axons displaying phosphatidylserine, an apoptotic marker, respectively. NGF scale bar: $1000 \mu \mathrm{m}$ and merge scale bar: $50 \mu \mathrm{m}$; BDNF scale bar: $500 \mu \mathrm{m}$ and merge scale bar: $50 \mu \mathrm{m}$. $\boldsymbol{B}$, Both NGF and BDNF deprivation induced a significant decrease in Calcein-AM-positive axonal area $(n=5$ embryos in NGF and $n=8$ embryos in BDNF from pooled litters) and a significant increase in Annexin-V area ( $n=5$ embryos in NGF deprivation $24 \mathrm{~h}$ and $n=10$ embryos in BDNF deprivation $24 \mathrm{~h}$ from pooled litters). The bar plots show mean, min/max, and 25/75\% for each panel, analyzed by two-tailed Mann-Whitney tests with ${ }^{\star} p<0.05,{ }^{\star *} p<0.01$, ${ }^{\star \star *} p<0.001$. $\boldsymbol{C}$, DRG explants cultured in NGF or BDNF were maintained in trophic media (ctr) or withdrawn from trophic support for $15 \mathrm{~h}$ (dep) before staining with Fluo-4 and imaged by epifluorescence microscopy. NGF scale bar: $1000 \mu \mathrm{m}$; BDNF scale bar: $200 \mu \mathrm{m}$. $\boldsymbol{D}$, Both NGF and BDNF deprivation induced a significant increase in axonal Fluo4 intensity ( $n=4$ embryos in NGF and $n=6$ embryos in BDNF from pooled litters). The Box plots show mean, min/max, and $25 / 75 \%$ for each panel, analyzed by two-tailed Mann-Whitney tests with ${ }^{*} p<0.05$.

in $B)$. It has been previously shown that NGF deprivation induces a large increase in axoplasmic $\mathrm{Ca}^{2+} \sim 15 \mathrm{~h}$ after deprivation (Johnstone et al., 2018, 2019) and here show that BDNF-withdrawal induces a similar elevation in axonal $\mathrm{Ca}^{2+}$ $15 \mathrm{~h}$ after trophic deprivation (Fig. $3 C$, quantified in $D$ ).

To characterize the neurotrophin receptor complement in DRG explants, protein lysates from E13.5 DRGs maintained in NGF or BDNF for $72 \mathrm{~h}$ were analyzed by immunoblot. DRGs cultured in NGF expressed abundant TrkA, TrkB, and p75NTR but low amounts of TrkC. In contrast, DRG neurons cultured in BDNF expressed abundant TrkB, TrkC, and p75NTR (Fig. 4A) but essentially no TrkA.

Previous studies have indicated that p75NTR is required for cell death of sympathetic neurons during development (Deppmann et al., 2008) but not for apoptosis of 
A

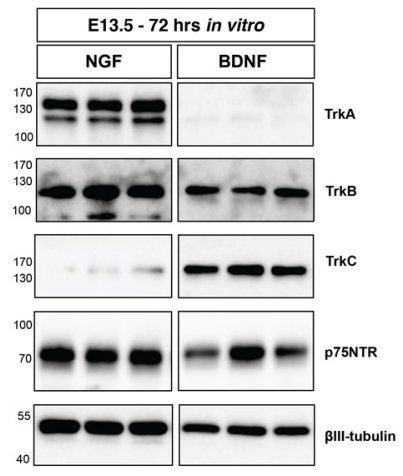

B

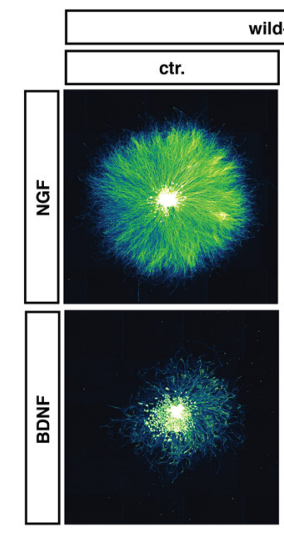

C

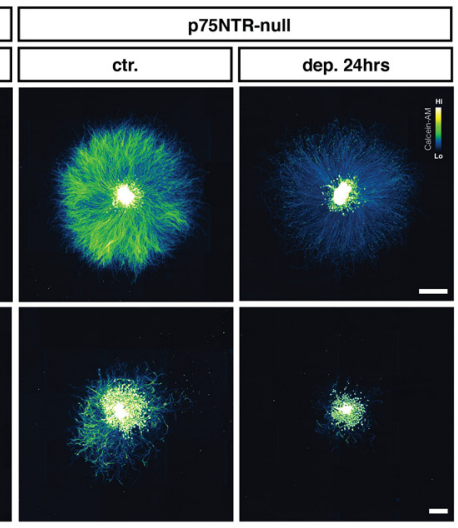

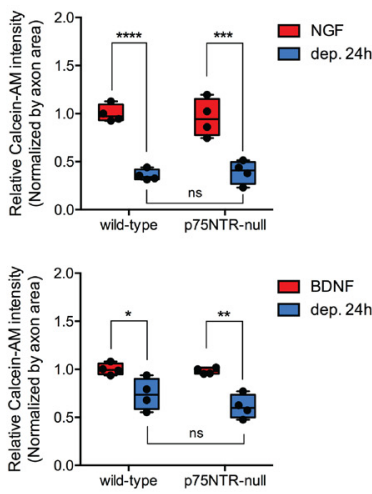

D
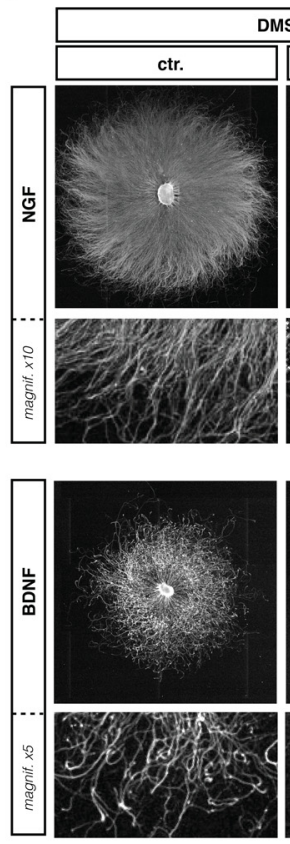

DMSO
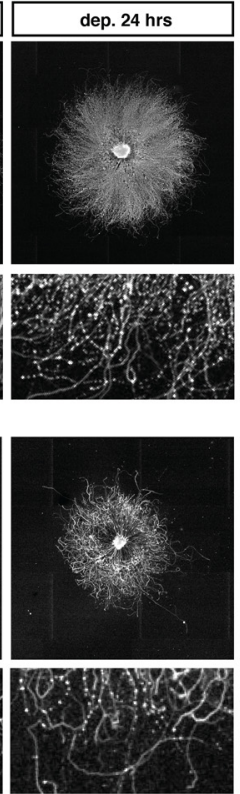

wild-type
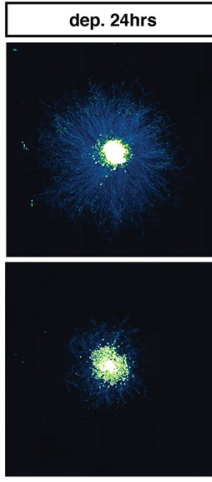

E
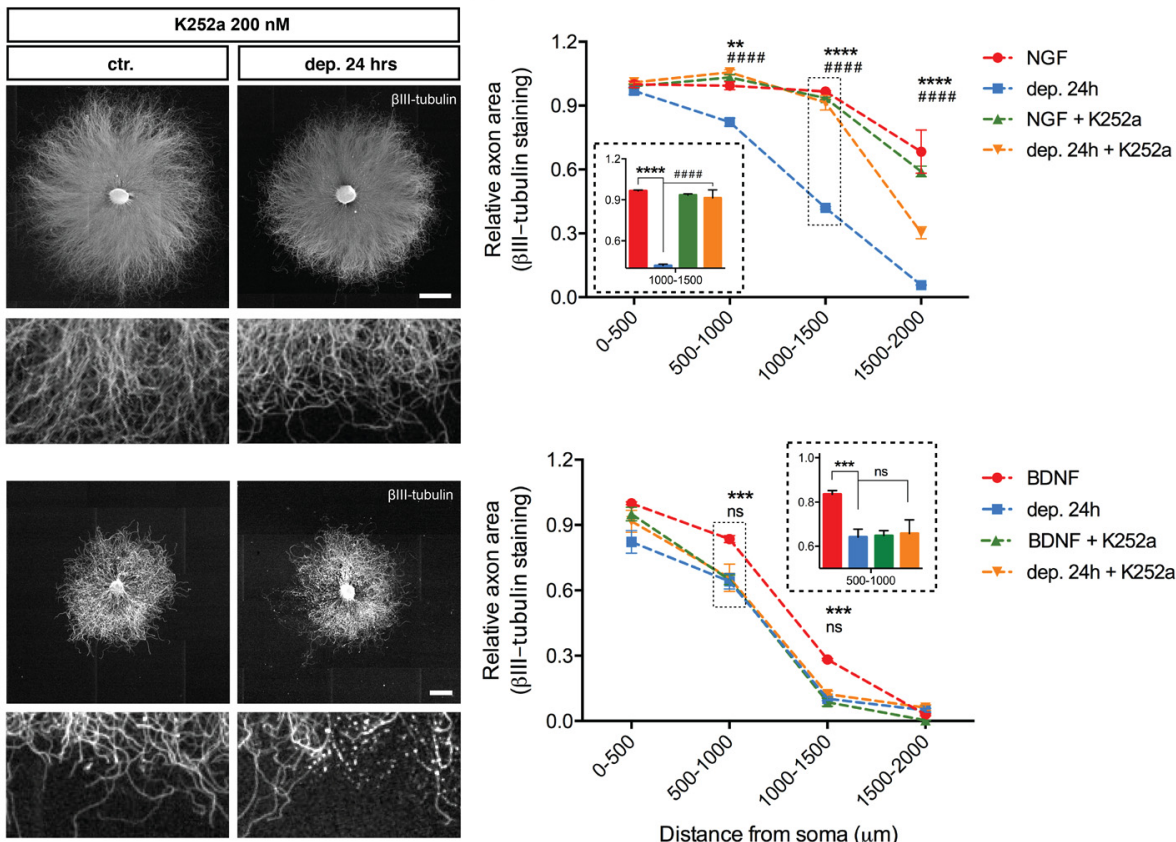

Distance from soma $(u \mathrm{~m})$

Figure 4. Trk receptor inhibition protects axons from NGF deprivation but not from BDNF deprivation, whereas p75NTR deficiency confers no protection to axons established in NGF or BDNF. A, Protein lysates collected from E13.5 DRG explants cultured in the presence of NGF $(12.5 \mathrm{ng} / \mathrm{ml})$ or BDNF $(37.5 \mathrm{ng} / \mathrm{ml})$ for $48 \mathrm{~h}$ were analyzed by immunoblot against TrkA, TrkB, TrkC, p75NTR, and $\beta$ III-tubulin. $\boldsymbol{B}$, p75NTR knock-out does not rescue axons from degeneration after NGF or BDNF withdrawal. DRG explants from mixed-genotyped E13.5 litters were cultured in the presence of NGF or BDNF for $48 \mathrm{~h}$ and then either maintained or withdrawal from trophic support for $24 \mathrm{~h}$ before being lived stained with Calcein-AM. NGF scale bar: $1000 \mu \mathrm{m}$; BDNF scale bar: $500 \mu \mathrm{m}$. C, Quantification of Calcein-AM intensity normalized by axonal area and relative to wild-type control. Non-significant difference was observed between wild-type and p75NTR-null DRG explants deprived of NGF or BDNF ( $n=4$ embryos in NGF and $n=4$ embryos in BDNF from pooled litters). Analyzed by two-way ANOVA and Tukey's post hoc comparison and plotted with median and SEM; ${ }^{*} p<0.05,{ }^{\star *} p<0.01,{ }^{* \star *} p<0.001,{ }^{* \star \star *} p<0.0001$. $\boldsymbol{D}$, DRG explants cultured in NGF or BDNF were either maintained in trophic media or withdrawn from trophic support with or without the Trk inhibitor K252a (200 nM) for $24 \mathrm{~h}$ before fixing, immunostaining for $\beta$ III-tubulin, and imaged by epifluorescence microscopy. NGF scale bar: $1000 \mu \mathrm{m}$; BDNF scale bar: $500 \mu \mathrm{m}$. $\boldsymbol{E}$, K252a rescued degeneration induced by NGF deprivation but not by BDNF deprivation. Quantification of axonal area as a function of the distance from the soma using Axoquant 2.0 and plotted in 500- $\mu \mathrm{m}$ binned segments relative to 0-500 $\mu \mathrm{m}$ NGF control (upper panel) or BDNF control (lower panel). The relative axonal area was analyzed by two-factor ANOVA followed by Tukey's post hoc comparison and plotted with mean and SEM ( $n=3$ embryos per condition for each condition; data shown are representative of three independent experiments); ${ }^{*}$ ctr. versus dep. $24 \mathrm{~h}$; \#dep. $24 \mathrm{~h}$ versus dep. $24 \mathrm{~h}+\mathrm{K} 252 \mathrm{a}$; ns: non-significant, ${ }^{* *} p<0.01,{ }^{* * *} p<0.001,{ }^{* \star * *} p<0.0001$. 
A
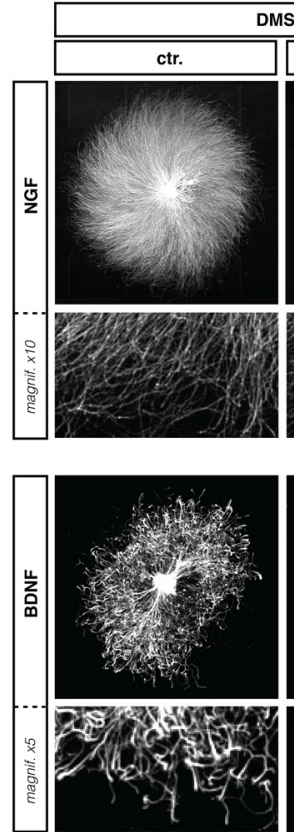

C
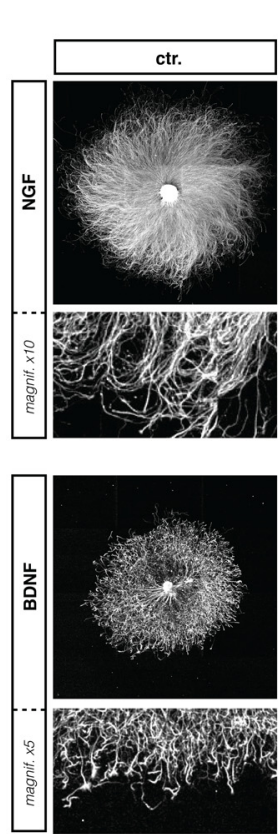

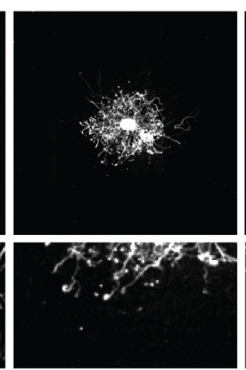

DMSO
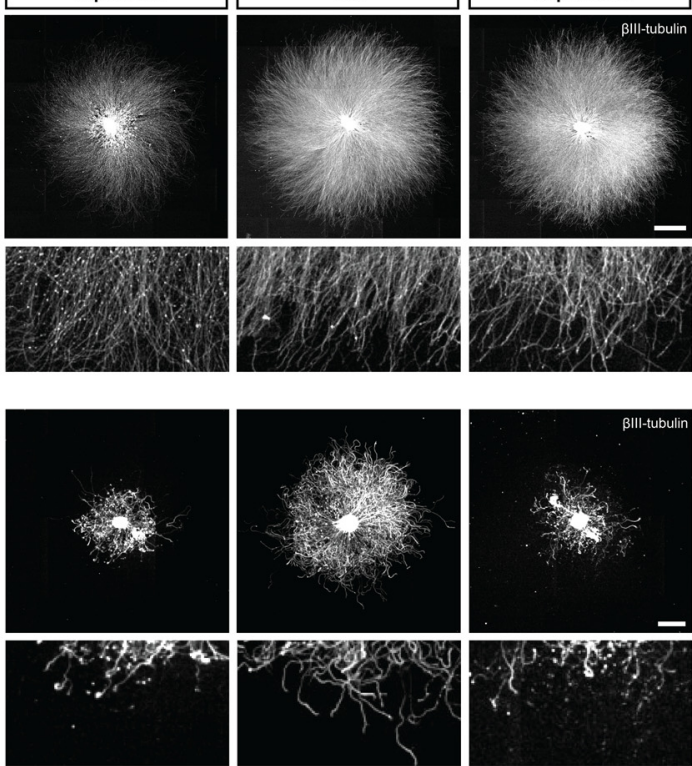

B
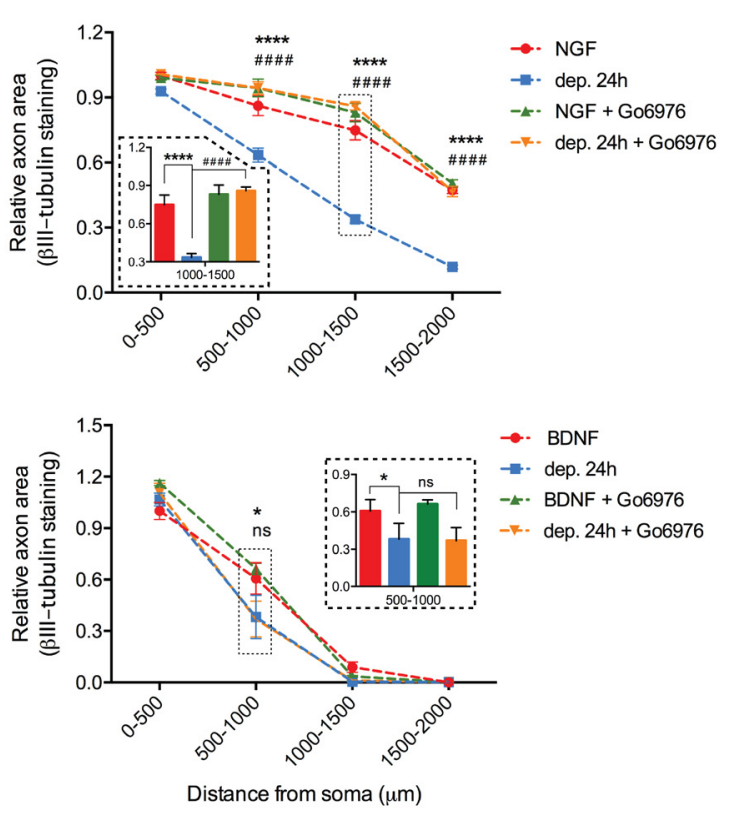

D
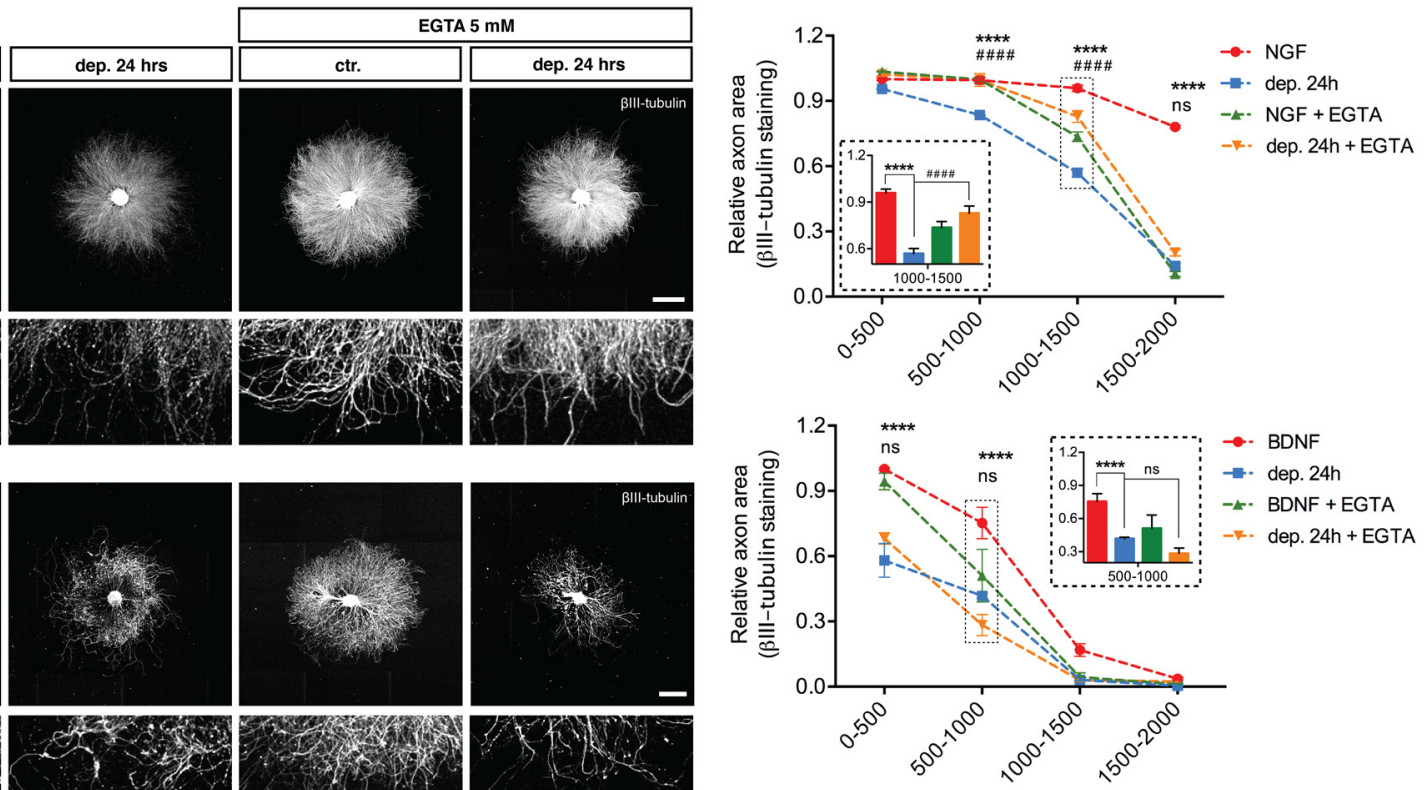

Distance from soma $(\mu \mathrm{m})$

Figure 5. PKC inhibitor Gö6976 and EGTA rescue degeneration induced by NGF deprivation but not BDNF deprivation. $\boldsymbol{A}$, DRG explants cultured in NGF or BDNF were either maintained in trophic media or withdrawn from trophic support with or without PKC inhibitor Gö6976 (10 $\mu \mathrm{M})$ for $24 \mathrm{~h}$ before fixing, immunostaining for $\beta$ Ill-tubulin, and imaged by epifluorescence microscopy. NGF scale bar: $1000 \mu \mathrm{m}$; BDNF scale bar: $500 \mu \mathrm{m}$. B, Quantification of axonal area as a function of the distance from the soma using Axoquant 2.0 (Johnstone et al., 2018) and plotted in 500- $\mu \mathrm{m}$ bins segments relative to 0-500 $\mu \mathrm{m}$ 48-h time point. The relative axonal area was analyzed by two-factor ANOVA followed by Tukey's post hoc comparison and plotted with mean and SEM ( $n=3$ embryos per condition for each condition; data shown are representative of three independent experiments); ${ }^{*}$ control versus deprived $24 \mathrm{~h}$; \#deprived $24 \mathrm{~h}$ versus deprived $24 \mathrm{~h}+$ Gö6976; ns: non-significant, ${ }^{\star} p<0.05,{ }^{\star \star \star *} p<0.0001$. C, DRG explants cultured in NGF or BDNF were either maintained in trophic media or withdrawn from trophic support with or without $\mathrm{Ca}^{2+}$ chelator EGTA (5 mM) for 24 $\mathrm{h}$ before fixing, immunostained for $\beta$ III-tubulin, and imaged by epifluorescence microscopy. NGF scale bar: $1000 \mu \mathrm{m}$; BDNF scale bar: $500 \mu \mathrm{m}$. D, Quantification of axonal area as a function of the distance from the soma using Axoquant 2.0 and plotted in $500-\mu \mathrm{m}$ binned segments. $\mathrm{Ca}^{2+}$ chelation rescued degeneration induced by NGF deprivation but not by BDNF deprivation. The relative axonal area was analyzed by two-factor ANOVA followed by Tukey's post hoc comparison and plotted with mean and SEM $(n=3$ 
continued

embryos per condition for each condition; data shown are representative of three independent experiments); ${ }^{*}$ ctr. versus dep. 24 h; \#dep. 24 h versus dep. 24 h + EGTA; ns: non-significant, ${ }^{\star \star \star *} p<0.0001$.

A
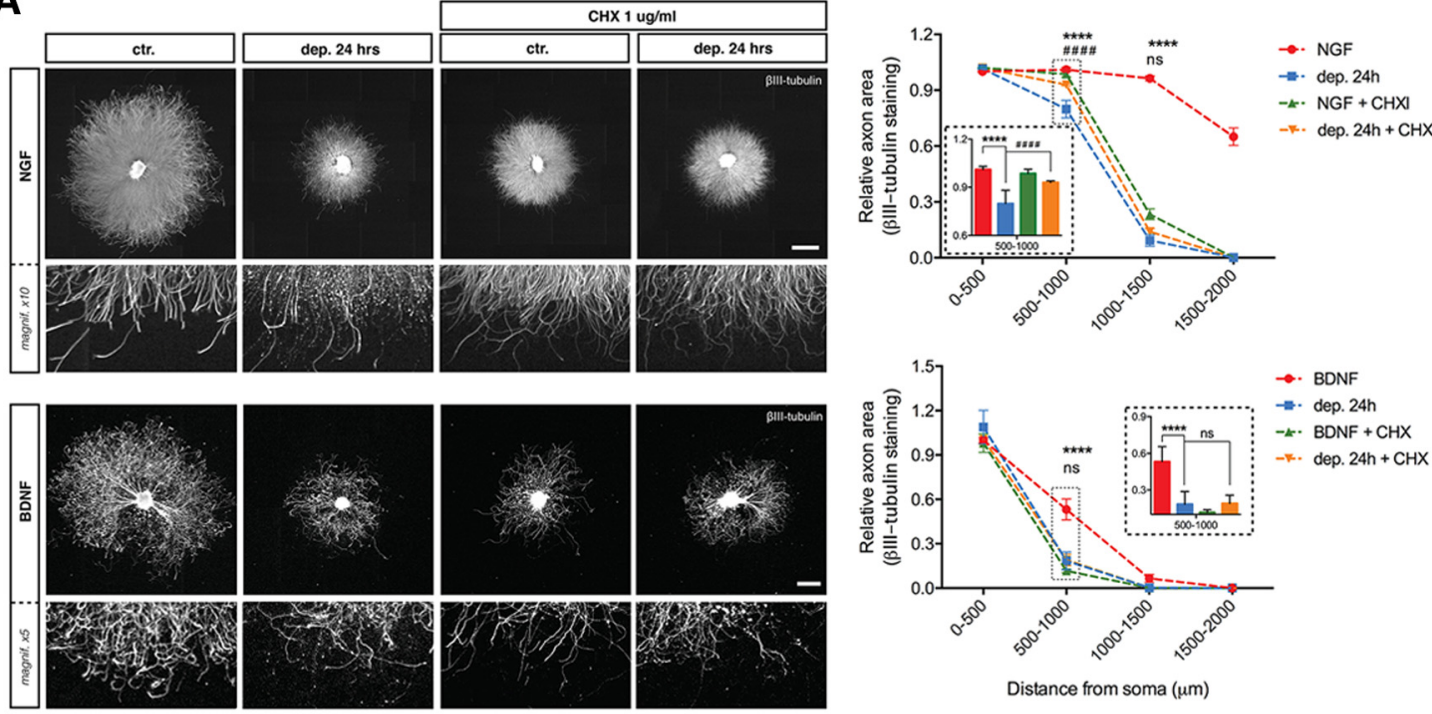

B
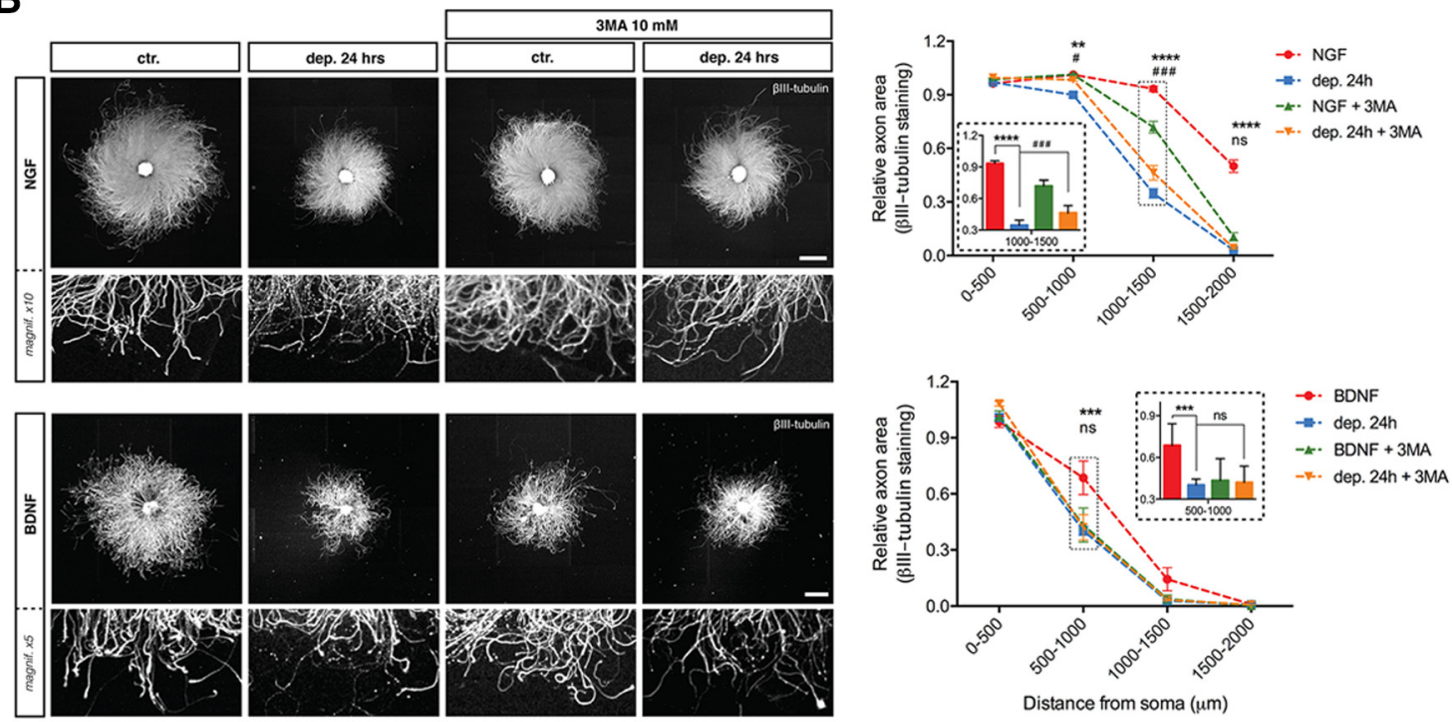

Figure 6. Translation, autophagy, necroptosis or Wallerian-like degeneration are not involved in BDNF deprivation-induced degeneration. $\boldsymbol{A}$, DRG explants cultured in NGF or BDNF were maintained in trophic media or withdrawn from trophic support with or without translation inhibitor $\mathrm{CHX}(1 \mu \mathrm{g} / \mathrm{ml})$ for $24 \mathrm{~h}$ before fixing, immunostaining for $\beta$ Ill-tubulin, and imaging by epifluorescence microscopy. NGF scale bar: $1000 \mu \mathrm{m}$; BDNF scale bar: $500 \mu \mathrm{m}$. Quantification of axonal area as a function of the distance from the soma plotted in 500- $\mu \mathrm{m}$ bins segments relative to $0-500 \mu \mathrm{m}$ BDNF control. CHX rescued degeneration induced by NGF deprivation but not by BDNF deprivation. The relative axonal area was analyzed by two-factor ANOVA followed by Tukey's post hoc comparison and plotted with mean and SEM ( $n=3$ embryos per condition for each condition; data shown are representative of three independent experiments); ${ }^{\star}$ ctr. versus dep. $24 \mathrm{~h}$; \#dep. $24 \mathrm{~h}$ versus dep. $24 \mathrm{~h}+\mathrm{CHX}$; ns: non-significant, ${ }^{* \star * *} p<0.0001 . \boldsymbol{B}$, DRG explants were withdrawn from trophic support with or without the autophagy inhibitor 3-MA (10 mM) for $24 \mathrm{~h}$ before being immunostained for $\beta$ III-tubulin. NGF scale bar: $1000 \mu \mathrm{m}$; BDNF scale bar: $500 \mu \mathrm{m}$. Quantification of axonal area as a function of the distance from the soma plotted in 500- $\mu \mathrm{m}$ bins segments relative to 0-500 $\mu \mathrm{m}$ BDNF control. 3-MA rescued degeneration induced by NGF deprivation but not by BDNF deprivation. The relative axonal area was analyzed by two-factor ANOVA followed by Tukey's post hoc comparison and plotted with mean and SEM $(n=3$ embryos per condition for each condition; data shown are representative of three independent experiments); ${ }^{*}$ ctr. versus dep. 24 h; \#dep. 24 h versus dep. 24 h $+3-M A$; ns: non-significant, ${ }^{*} p<0.05$, ${ }^{* \star} p<0.01,{ }^{* \star *} p<0.001,{ }^{* \star \star *} p<0.0001$ 
C
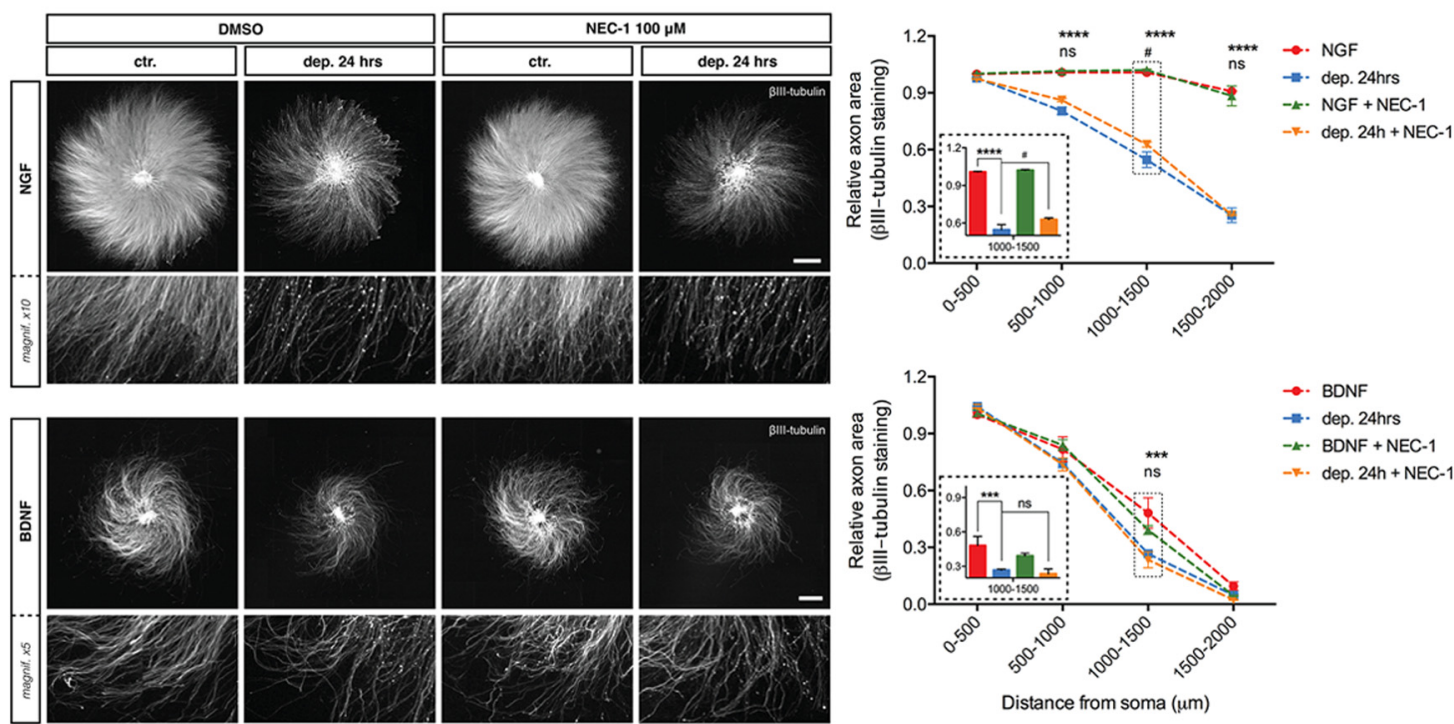

-. BDNF

$\rightarrow$ dep. $24 \mathrm{hrs}$

-2. $B D N F+N E C-1$

-r. dep. $24 h+N E C-1$

D
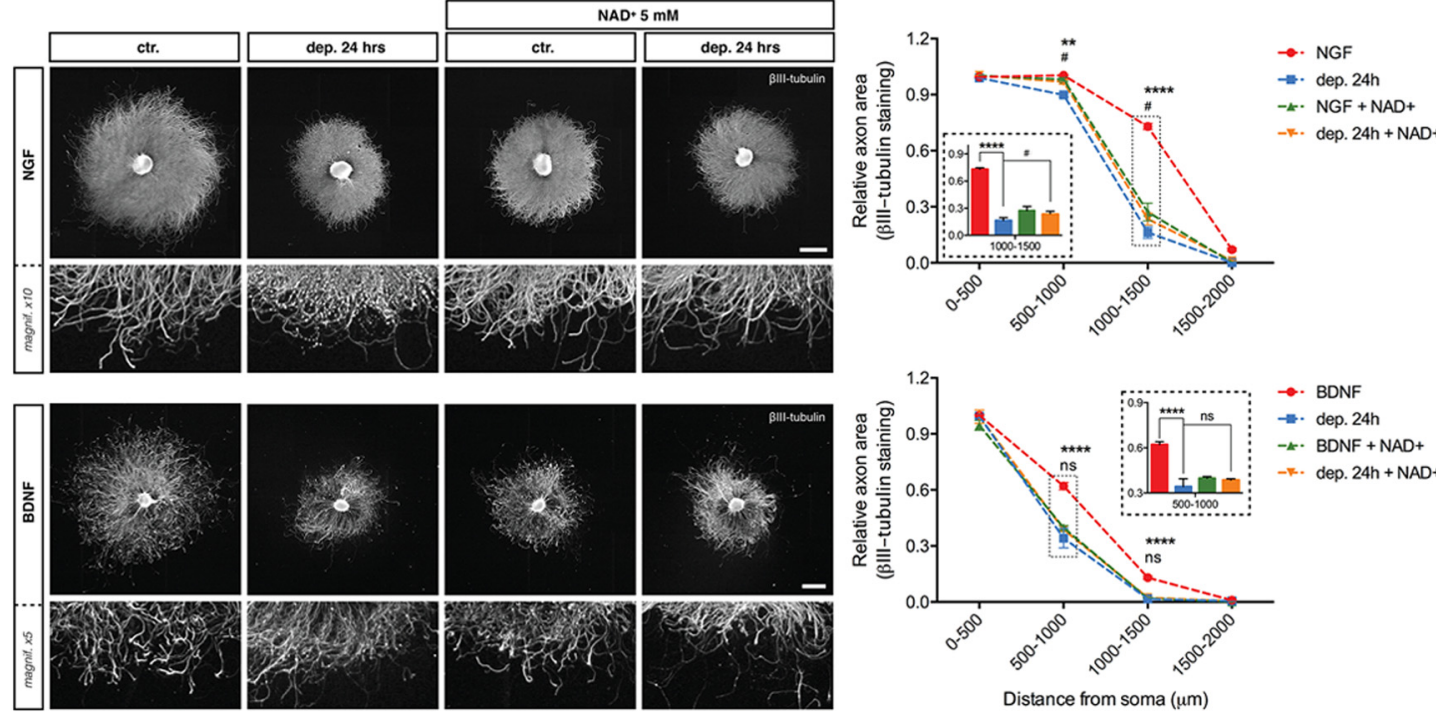

Figure 6(Continued). C, DRG explants were withdrawn from trophic support with or without the necroptosis inhibitor NEC-1 (100 $\mu \mathrm{M})$ for $24 \mathrm{~h}$ before being immunostained for $\beta$ III-tubulin. NGF scale bar: $1000 \mu \mathrm{m}$; BDNF scale bar: $500 \mu \mathrm{m}$. Quantification of axonal area as a function of the distance from the soma plotted in 500- $\mu \mathrm{m}$ binned segments relative to 0-500 $\mu \mathrm{m}$ BDNF control. NEC-1 slightly rescued degeneration induced by NGF deprivation but not by BDNF deprivation. The relative axonal area was analyzed by two-factor ANOVA followed by Tukey's post hoc comparison and plotted with mean and SEM ( $n=3$ embryos per condition for each condition; representative of three independent experiments); ${ }^{*}$ ctr. versus dep. 24 h; \#dep. 24 h versus dep. 24 h + NEC-1; ns: nonsignificant, ${ }^{*} p<0.05,{ }^{* * *} p<0.001,{ }^{* * *} p<0.0001$. $\boldsymbol{D}$, DRG explants were withdrawn from trophic support with or without NAD $+(5$ $\mathrm{mm}$ ) for $24 \mathrm{~h}$ before being immunostained for $\beta$ III-tubulin. NGF scale bar: $1000 \mu \mathrm{m}$; BDNF scale bar: $500 \mu \mathrm{m}$. Quantification of axonal area as a function of the distance from the soma plotted in 500- $\mu \mathrm{m}$ bins segments relative to $0-500 \mu \mathrm{m}$ BDNF control. NAD+ rescued degeneration induced by NGF deprivation but not by BDNF deprivation. The relative axonal area was analyzed by two-factor ANOVA followed by Tukey's post hoc comparison and plotted with mean and SEM $(n=3$ embryos per condition for each condition; data shown are representative of three independent experiments); ${ }^{*}$ ctr. versus dep. $24 \mathrm{~h}$; \#dep. $24 \mathrm{~h}$ versus dep. $24 \mathrm{~h}+\mathrm{NAD}+$; ns: non-significant, ${ }^{*} p<0.05,{ }^{* *} p<0.01,{ }^{* * *} p<0.0001$.

DRG sensory neurons. p75NTR has also been shown to be required for sympathetic neuron axon degeneration (Bamji et al., 1998; Singh et al., 2008). To determine whether p75NTR is required for axonal loss after NGF or BDNF deprivation in DRG axons, we assessed axonal loss in DRGs from p75NTRnull embryos (Fig. 4B). When maintained and then withdrawn from NGF or BDNF, the degree of axonal degeneration was the same in wild-type and p75NTR-null DRGs (Fig. 4C), ruling out a direct role for p75NTR in axon loss induced by neurotrophin withdrawal.

TrkA and TrkC have been implicated as dependence receptors (Nikoletopoulou et al., 2010), and recent studies 
A
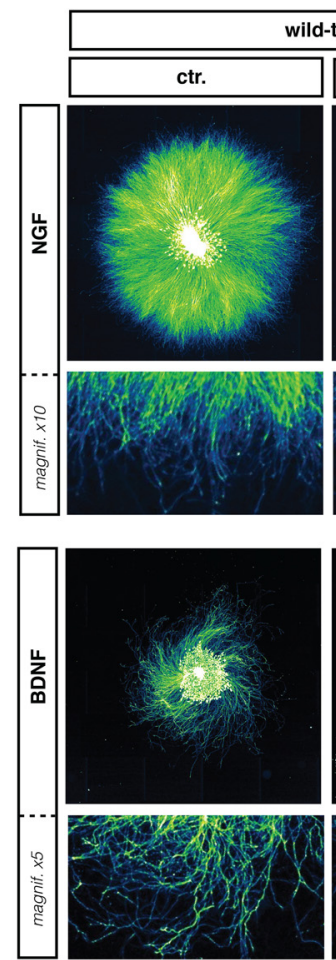

wild-type
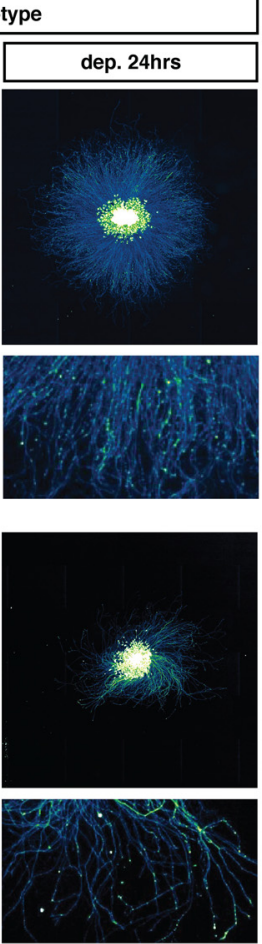

B
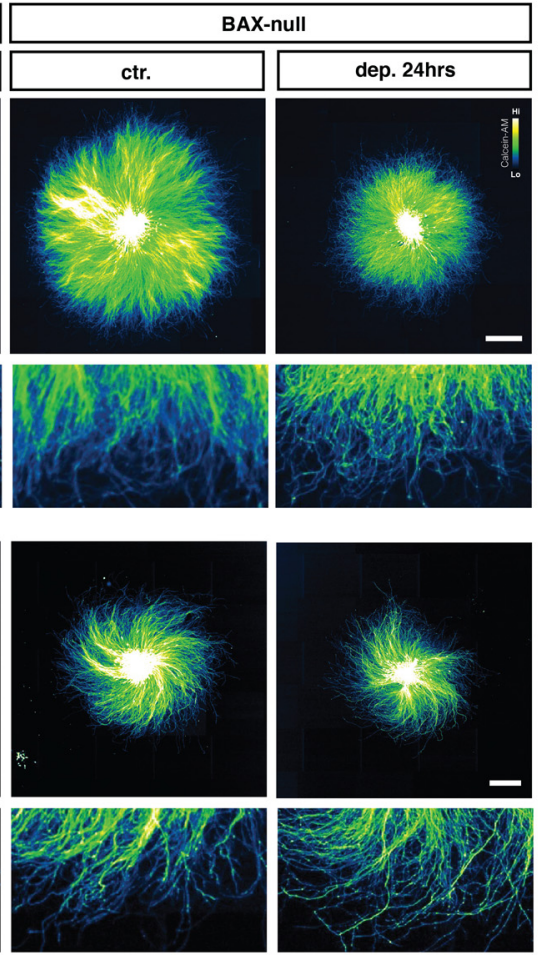
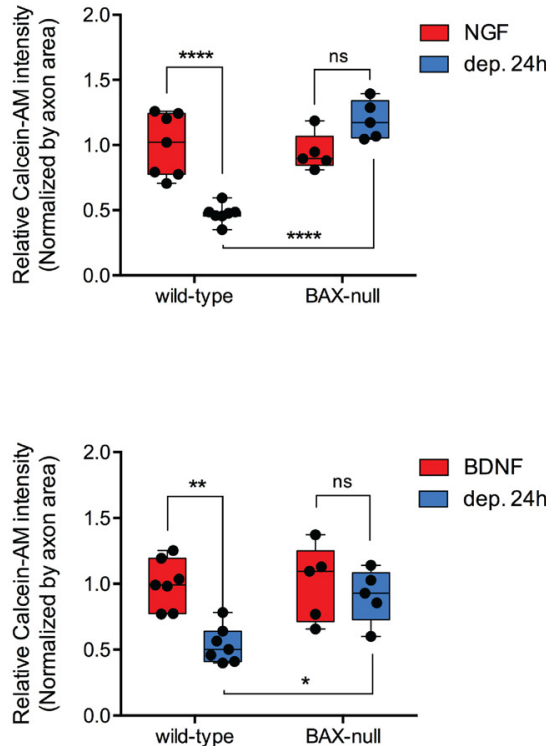

Figure 7. NGF and BDNF deprivation-induced degeneration require BAX. $\boldsymbol{A}$, DRG explants from mixed-genotyped E13.5 litters were cultured in the presence of NGF or BDNF for $48 \mathrm{~h}$ and then either maintained or withdrawn from trophic support for $24 \mathrm{~h}$ before being lived stained with Calcein-AM. NGF scale bar: $1000 \mu \mathrm{m}$; BDNF scale bar: $500 \mu \mathrm{m}$. B, Quantification of Calcein-AM intensity normalized by axonal area and relative to wild-type control. A significant increase in Calcein-AM intensity was observed in both NGF or BDNF deprived BAX-null DRG explants compared with their deprived wild-type counterparts $(n=7$ embryos in NGF/BDNF ctr., $n=5$ embryos in NGF/BDNF dep. 24 h, from pooled litters). Data were analyzed by two-way ANOVA and Tukey's post hoc comparison and plotted with median and SEM ns: non-significant, ${ }^{\star} p<0.05,{ }^{* *} p<0.01,{ }^{* * \star *} p<0.0001$.

have suggested that NGF deprivation activates a TrkAdependent apoptotic signaling pathway (Feinberg et al., 2017). Consistent with this, Figure $4 D, E$ shows that a low concentration of the pan-Trk inhibitor K252a (200 nM) rescues NGF deprivation induced axon degeneration of DRG sensory neurons but has no effect on BDNF deprivationinduced DRG axon degeneration (Fig. $4 D$, quantified in $E$ ). These results are consistent with previous findings showing that TrkB does not have dependence receptor activity (Nikoletopoulou et al., 2010).

To begin to discern signaling mechanisms driving BDNF deprivation-induced axon loss, we tested several compounds known to inhibit NGF withdrawal-induced axon degeneration or to inhibit neuronal cell death. PKC inhibitor Gö6976 rescues NGF deprivation-induced apoptosis (Johnstone et al., 2019) but had no effect on BDNF deprivation (Fig. $5 A$, quantified in $B$ ). Likewise, the $\mathrm{Ca}^{2+}$ chelator EGTA is a potent inhibitor of axon loss induced by NGF withdrawal in DRG neurons (Johnstone et al., 2018) but did not protect against BDNF deprivation (Fig. $5 C$, quantified in $D$ ). The translation inhibitor $\mathrm{CHX}$ also significantly protects axons from degeneration induced by NGF deprivation (Fig. 6A) but has no effect on axon degeneration induced by BDNF withdrawal. Finally, neither the autophagy inhibitor 3-MA, the necroptosis inhibitor
NEC-1 nor NAD+ blocked BDNF withdrawal-induced axonal degeneration of DRG sensory neurons (Fig. $6 B-D$ ).

$B A X$ is a central player in neuronal apoptosis and crucial for NGF deprivation-induced axonal degeneration (Patel et al., 2000; Schoenmann et al., 2010; Simon et al., 2012). To address the role of BAX in BDNF-deprived DRG sensory neurons, $B A X$-null DRG neurons were maintained in NGF or BDNF and then deprived of trophic support. Figure 7 shows that axons lacking BAX were significantly protected from degeneration induced by NGF and BDNF deprivation (Fig. $7 A$, quantified in $B$ ).

Caspase-3 is crucial for NGF deprivation-induced axonal degeneration (Simon et al., 2012; Unsain et al., 2013) and the requirement for BAX in BDNF withdrawal-induced axonal loss suggests that caspases may also play a role in axonal degeneration induced by BDNF deprivation. However, Figure $8 A$ shows that while caspase inhibition efficiently rescued axons from NGF deprivation, two distinct pan-caspase inhibitors (Boc-D-fmk and zVAD-fmk) did not reduce axonal degeneration in neurons that were maintained and then withdrawn from BDNF (Figs. $8 A$, quantified in $B$, and $9 A$, quantified in $B$ ). Correspondingly, NGF deprivation decreased levels of pro-caspase-3 and increased cleaved caspase- 3 , whereas levels of procaspase- 3 and cleaved caspase- 3 did not change in 
A
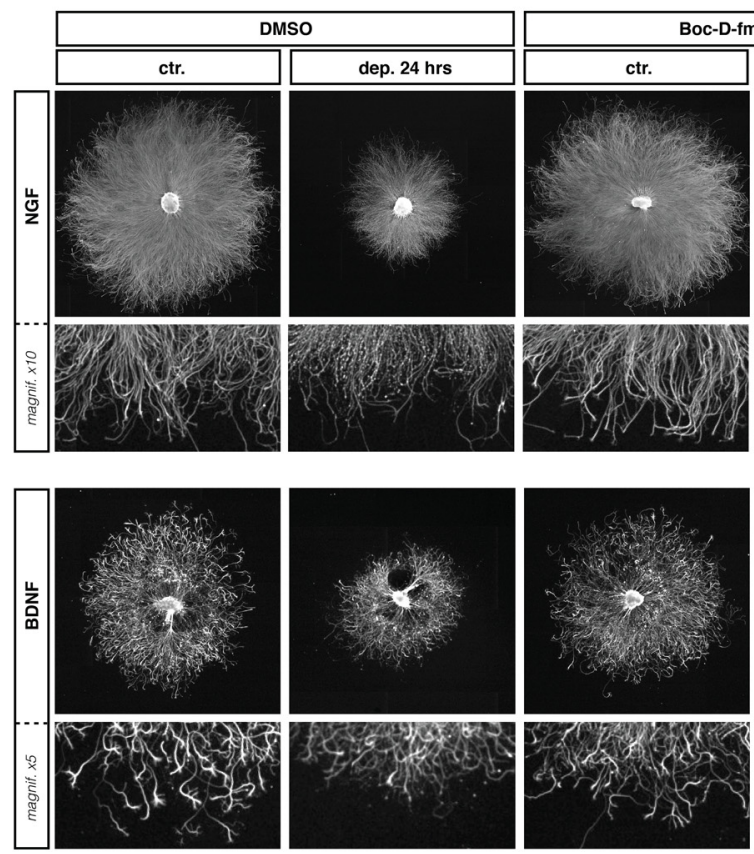

B
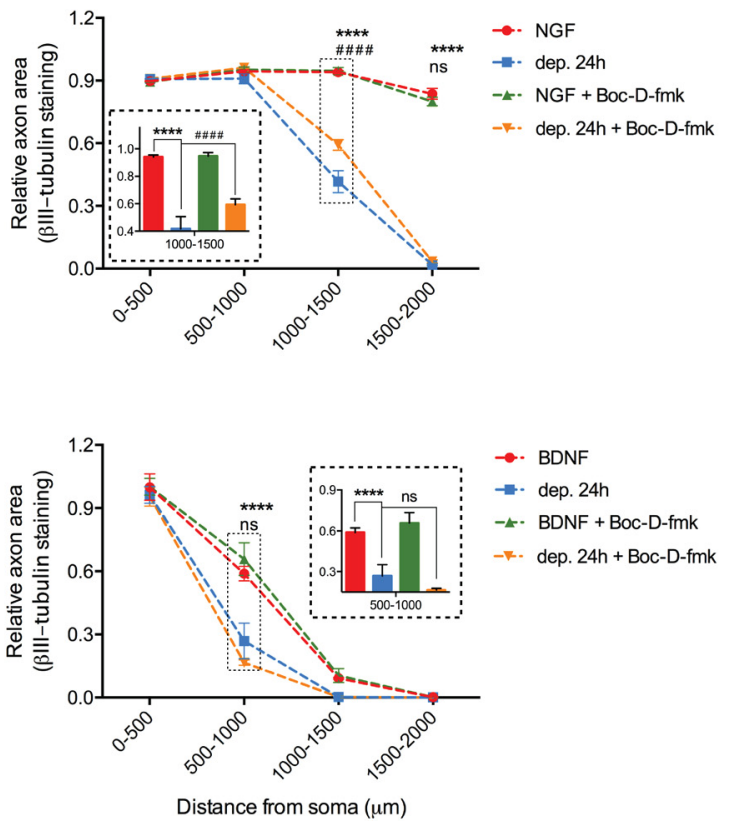

Figure 8. pan-Caspase inhibition does not block degeneration induced by BDNF deprivation. $\boldsymbol{A}$, DRG explants cultured in NGF or BDNF were maintained in trophic media or were withdrawn from trophic support with or without pan-caspase inhibitor Boc-D-fmk $(10 \mu \mathrm{M})$ for $24 \mathrm{~h}$ before fixing, immunostaining for $\beta$ III-tubulin, and imaging by epifluorescence microscopy. NGF scale bar: $1000 \mu \mathrm{m}$; BDNF scale bar: $500 \mu \mathrm{m}$. B, Quantification of axonal area as a function of the distance from the soma was performed using Axoquant 2.0 (Johnstone et al., 2018) and plotted in 500- $\mu \mathrm{m}$ binned segments relative to 0-500 $\mu \mathrm{m}$ NGF/BDNF controls. Pan-caspase inhibitor Boc-D-fmk rescued degeneration induced by NGF deprivation but not by BDNF deprivation. The relative axonal area was analyzed by two-factor ANOVA followed by Tukey's post hoc comparison and plotted with mean and SEM ( $n=3$ for each condition; data shown are representative of three independent experiments); *ctr. versus dep. $24 \mathrm{~h}$; \#dep. $24 \mathrm{~h}$ versus dep. $24 \mathrm{~h}+$ BocD-fmk; ns: non-significant, ${ }^{* \star \star *} p<0.0001$.

neurons maintained and then withdrawn from BDNF for 15, 24 and 30 h (Fig. 9C; data not shown). Taken together, these results indicate that BAX activity mediates BDNF deprivation-induced axonal degeneration through a caspase-independent pathway.

Several reports have shown that BAX can facilitate production of mitochondrial ROS (Kirkland and Franklin, 2001, 2007; Kirkland et al., 2002, 2010). To explore whether ROS play a role in neurotrophin deprivation-induced axonal degeneration, axons maintained in NGF or BDNF were exposed to NAC, a ROS scavenger, and then withdrawn from trophic support. Figure 10 shows that axonal degeneration induced by either NGF or BDNF deprivation was blocked in the presence of NAC, indicating that ROS are required for axonal degeneration induced by neurotrophin deprivation.

\section{Discussion}

The mammalian PNS has proven a useful system for identifying specific mechanisms that are required for developmental neuronal degeneration. Substantial understanding of processes that mediate neuronal cell death and axonal destruction has been obtained from analyses of NGF-dependent DRG neurons maintained in vitro. However, less is known about signaling pathways that lead to the developmental loss of other sensory neuron populations. In this study, we have examined mechanisms that promote the developmental degeneration of BDNF-dependent sensory neurons. Our observations show that BDNF-dependent DRG sensory neurons employ destructive mechanisms distinct from those employed by NGF-dependent sensory neurons.

Growth differences in NGF-dependent and BDNFdependent DRG populations. Several studies point to BDNF as a key trophic factor required to sustain the survival of different neuronal populations in vivo and in vitro (Johnson et al., 1986; Kalcheim et al., 1987; Liebl et al., 1997). Cranial sensory neurons are highly dependent on BDNF for survival and growth (Hellard et al., 2004), whereas only a subpopulation of DRG sensory neurons requires BDNF for survival during development (Huber et al., 2000; Valdés-Sánchez et al., 2010). Here, we showed that BDNF supports the survival and growth of neurons within E13.5 DRG explants, with neurite length steadily increasing with the time of trophic factor exposure. However, BDNF-dependent outgrowth was considerably less than that supported by NGF, consistent with the observation that only $8 \%$ of DRG neurons are TrkB+, while $80 \%$ are TrkA+ (Fariñas et al., 1998; Ernsberger, 2009). Thus, in the absence of NGF, the vast majority of DRG sensory neurons degenerate, leaving behind a small number of TrkB + neurons. The reduced capacity of BDNF to 
A
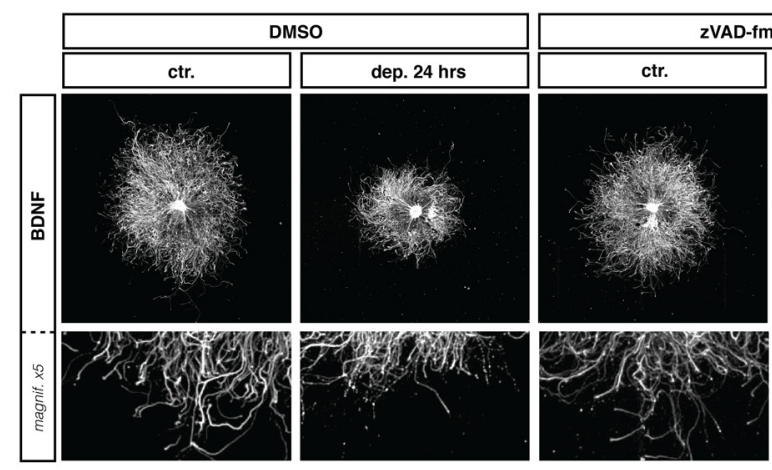

C

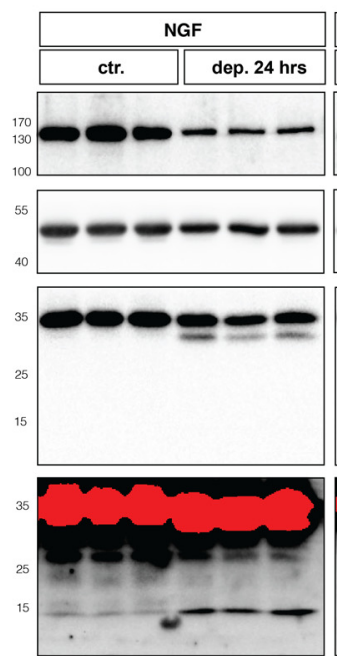

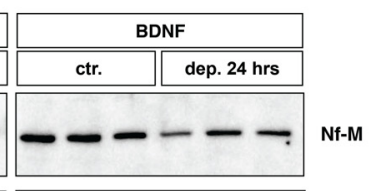
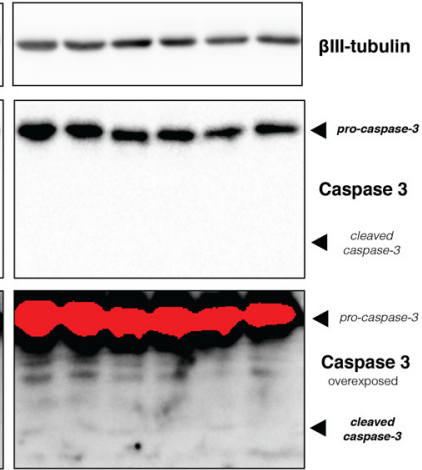

B

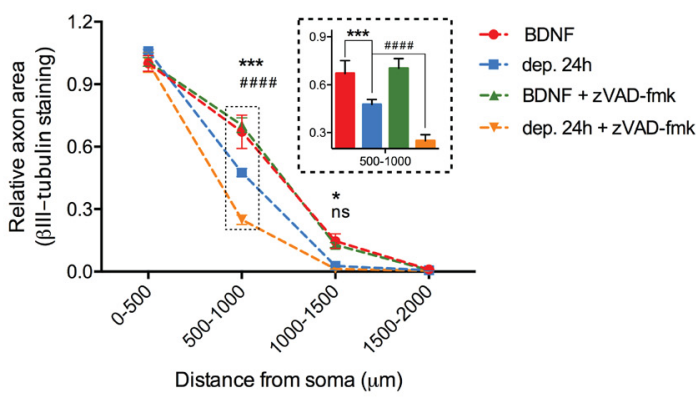

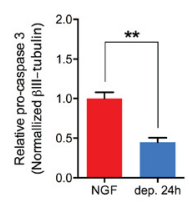

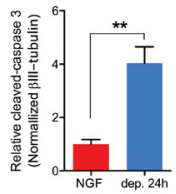

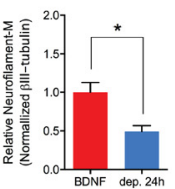
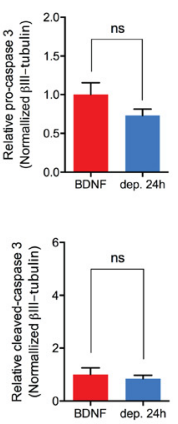

Figure 9. Cleaved form of executioner caspase-3 does not increase during BDNF deprivation. $\boldsymbol{A}$, DRG explants cultured in NGF or BDNF were either maintained in trophic media or withdrawn from trophic support with or without pan-caspase inhibitor zVAD-fmk $(20 \mu \mathrm{M})$ for $24 \mathrm{~h}$ before fixing, immunostaining for $\beta$ Ill-tubulin, and imaged by epifluorescence microscopy. BDNF scale bar: $1000 \mu \mathrm{m}$. B, Quantification of axonal area as a function of the distance from the soma plotted in $500-\mu \mathrm{m}$ bins segments relative to $0-500 \mu \mathrm{m}$ BDNF control. Pan-caspase inhibitor zVAD-fmk does not rescues degeneration induced by BDNF deprivation. The relative axonal area was analyzed by two-factor ANOVA followed by Tukey's post hoc comparison and plotted with mean and SEM ( $n=3$ embryos per condition for each condition; data shown are representative of three independent experiments); ${ }^{*} c t r$. versus dep. 24 h; \#dep. 24 h versus dep. 24 h + zVAD-fmk; ns: non-significant, ${ }^{*} p<0.05$, ${ }^{\star \star \star} p<0.001$, ${ }^{* \star \star *} p<0.0001$. C, Protein lysates collected from E13.5 DRG explants cultured in the presence of NGF $(12.5 \mathrm{ng} / \mathrm{ml})$ or BDNF $(37.5 \mathrm{ng} / \mathrm{ml})$ for $48 \mathrm{~h}$ were maintained or withdrawn from trophic support for $24 \mathrm{~h}$ and then analyzed by immunoblot against neurofilament-M (Nf-M) and caspase-3. Levels of NfM significantly deceased after either NGF and BDNF deprivation but only NGF deprived DRG lysates show a significant change in pro-caspase-3 and cleaved caspase-3 levels. Data were analyzed by two-tailed Mann-Whitney plotted with mean and SEM ( $n=3$ embryos per condition for each condition; representative of three independent experiments); ns: non-significant, ${ }^{*} p<0.05$, ${ }^{* *} p<0.01$.

promote neurite extension in culture may also reflect the fact that TrkB, but not TrkA, is downregulated after exposure and binding to its ligand (Sommerfeld et al., 2000; Haapasalo et al., 2002) and that BDNF activates Ras considerably less effectively than NGF (Borasio et al., 1989; Carter et al., 1995).

Trophic deprivation-induced degeneration of BDNFdependent DRG sensory neurons. To mimic BDNF deprivation that occurs during embryonic development, E13.5 DRGs were maintained in BDNF and then withdrawn from the factor. A function blocking monoclonal antibody directed against BDNF was deployed to inactivate any residual BDNF remaining. BDNF deprivation resulted in neurite blebbing, a hallmark morphology of degenerating neurites, and caused a significant reduction of area occupied by neurites. Axonal degeneration provoked by BDNF deprivation was confirmed using the live dye Calcein-AM and by staining with Annexin-V, which detects phosphatidylserine on the outer leaflet of the plasma membrane, a prototypical signal driving phagocytosis of cells undergoing cell death (Wakatsuki and Araki, 2017; Shacham-Silverberg et al., 2018). Calcein$\mathrm{AM}$ is a sensitive staining technique to quantify axonal integrity. However, Calcein-AM binds calcium after being 


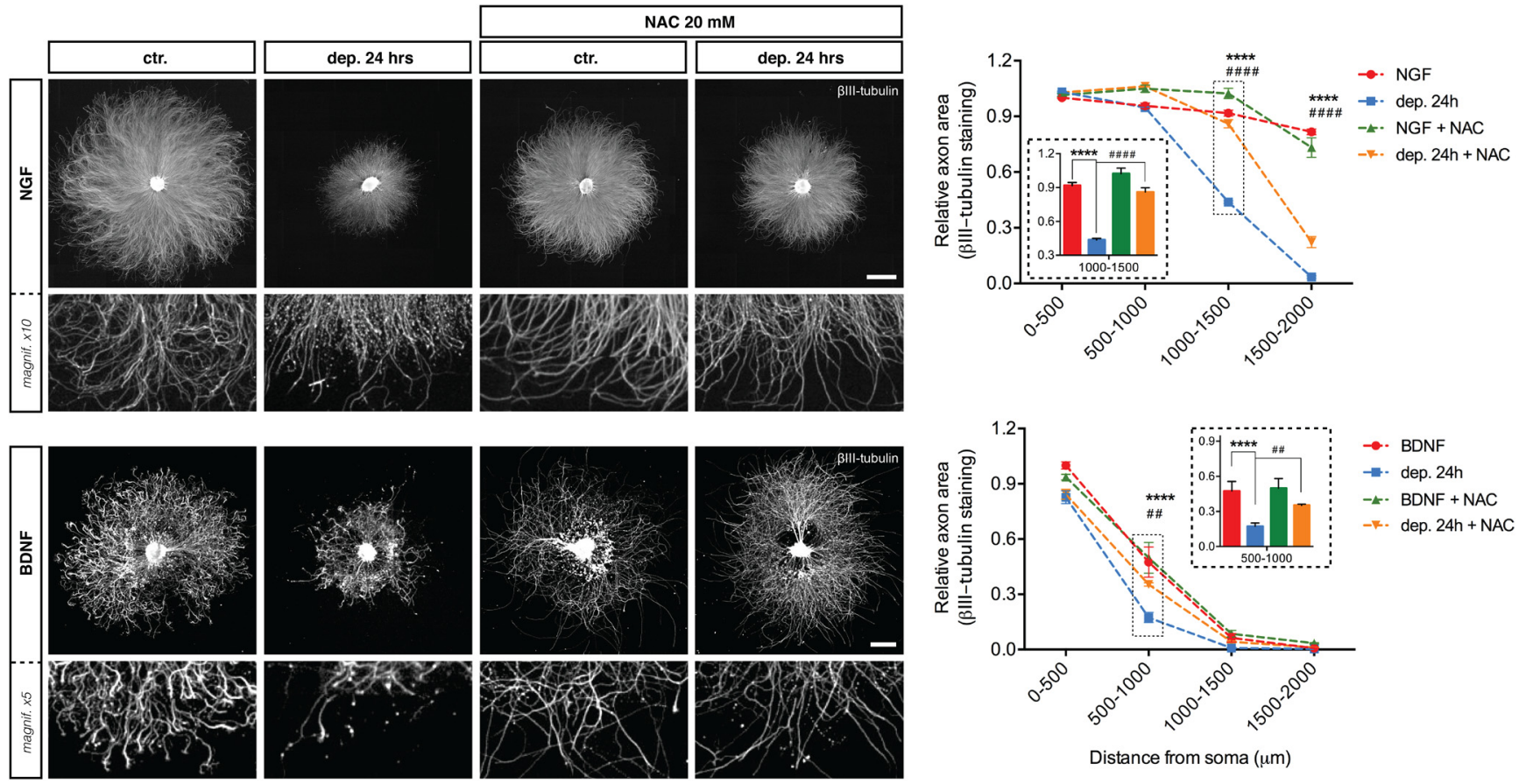

Figure 10. ROS are required for axon degeneration induced by BDNF deprivation. $\boldsymbol{A}$, DRG explants cultured in NGF or BDNF were either maintained in trophic media or withdrawn from trophic support with or without ROS scavenger NAC (20 mM) for $24 \mathrm{~h}$ before fixing, immunostaining for $\beta$ III-tubulin, and imaged by epifluorescence microscopy. NGF scale bar: $1000 \mu \mathrm{m}$; BDNF scale bar: $500 \mu \mathrm{m}$. B, Quantification of axonal area as a function of the distance from the soma and plotted in $500-\mu \mathrm{m}$ bins segments relative to $0-500 \mu \mathrm{m} 48-\mathrm{h}$ time point. NAC rescued degeneration induced by NGF deprivation and BDNF deprivation. The relative axonal area was analyzed by two-factor ANOVA followed by Tukey's post hoc comparison and plotted with mean and SEM ( $n=3$ embryos for each condition; data shown are representative of three independent experiments); *ctr. versus dep. 24 h; \#dep. $24 \mathrm{~h}$ versus dep. $24 \mathrm{~h}+\mathrm{NAC} ;{ }^{\star \star} p<0.01,{ }^{\star \star \star \star} p<0.0001$

hydrolyzed by intracellular esterase and its use was not compatible with some of our treatments (e.g., EGTA). Therefore, Calcein-AM staining was used to follow the effect of p75NTR or BAX deficiency on axonal integrity during trophic deprivation conditions and the effects of drugs on axonal degeneration was studied based on $\beta$ III-tubulin staining and quantified with Axoquant 2.0 (as described in Johnstone et al., 2018).

How does BDNF deprivation trigger degeneration in BDNF-dependent sensory neurons? Several studies have indicated that unliganded TrkA promotes proapoptotic signaling in sympathetic and sensory neurons withdrawn from NGF (Tauszig-Delamasure et al., 2007; Nikoletopoulou et al., 2010; Feinberg et al., 2017). In this sense, TrkA can be considered a "dependence receptor" that promotes survival signaling when bound by ligand but drives death signaling on ligand withdrawal (Nikoletopoulou et al., 2010). Here, we showed that the pan-Trk kinase inhibitor K252a prevented degeneration normally induced by NGF deprivation but had no effect on degeneration induced by BDNF deprivation, indicating that TrkA, but not TrkB, behaves as a dependence receptor. This finding agrees with those of Barde's group who found that TrkA and TrkC behave as dependence receptors but the BDNF receptor TrkB is incapable of doing so (Nikoletopoulou et al., 2010).

We also questioned the role of p75NTR in BDNF deprivation. Depending on the cellular and molecular context, the low-affinity neurotrophin receptor can drive prosurvival or prodeath signaling (Roux and Barker, 2002; Mehlen and Bredesen, 2004). Although p75NTR is crucial for sympathetic neuronal remodeling during embryonic development (Bamji et al., 1998; Singh et al., 2008), here we found that p75NTR had no effect on degeneration of sensory neurons maintained and then withdrawn from either NGF or BDNF.

PKC plays an indispensable role in DRG degeneration induced by NGF withdrawal (Johnstone et al., 2019) but PKC inhibitors had no effect on BDNF-withdrawal induced degeneration. Likewise, $\mathrm{CHX}$, a potent blocker of NGF withdrawal-induced degeneration had no effect on BDNF-withdrawal induced deprivation. Therefore, degeneration mechanisms of sensory neurons maintained and then withdrawn from BDNF are fundamentally distinct from those in NGF-dependent sensory neurons.

Role of $\mathrm{Ca}^{2+}$ in BDNF deprivation induced degeneration of BDNF-dependent DRG sensory neurons. In NGF-dependent DRG neurons, extracellular $\mathrm{Ca}^{2+}$ chelation blocks both the axoplasmic $\mathrm{Ca}^{2+}$ rise and the subsequent degenerative process that normally occur on NGF withdrawal (Johnstone et al., 2018, 2019). Here, we showed that BDNF deprivation induces $\mathrm{Ca}^{2+}$ rise in neurites of BDNF-dependent DRG explants yet $\mathrm{Ca}^{2+}$ chelation with EGTA did not rescue BDNF deprivation-induced degeneration. We observed that $\mathrm{Ca}^{2+}$ chelation in non- 
deprived DRG explants induced growth arrest and previous work has established that the ability of BDNF to sustain neuronal survival is reduced in comparison to NGF (Borasio et al., 1989; Carter et al., 1995). These results suggest a delicate homeostasis within BDNF-dependent DRG neurons. The lack of $\mathrm{Ca}^{2+}$ paired with the trophic support deprivation could, in these sensitive cells, favor degeneration instead of protection. Therefore, our results do not completely rule out an active role of $\mathrm{Ca}^{2+}$ in the degenerative mechanism of BDNF-deprived DRG neurons.

ROS play a central role in the degeneration induced by BDNF deprivation. ROS were initially described solely as toxic cellular by-products, but a growing body of evidence has established ROS as endogenous modulators of numerous physiological functions (Wilson et al., 2018). A recent study showed that NGF deprivation in sensory neurons induces ROS production through a PKC/NOX pathway and that ROS scavengers rescue degeneration of NGF-dependent sensory neurons after trophic deprivation (Johnstone et al., 2019). In the present work we showed that the antioxidant NAC partially protects DRG neurons from BDNF deprivation, suggesting that ROS play a role in the degeneration of BDNF-dependent sensory neurons. However, blocking PKC during BDNF deprivation had no effect on degeneration, indicating that the contribution of NOX-derived ROS to BDNF degeneration pathway is likely minor. Consistent with this, we found that NOX inhibitors that block NGF withdrawal-induced degeneration had no effect on BDNF-withdrawalinduced degeneration (data not shown).

Aside from NOX complexes, the other major source of ROS in the cell is mitochondria. Our results show that $B A X$ is required for BDNF deprivation-induced degeneration of DRG neurons in vitro, consistent with in vivo data showing the importance of BAX during developmental cell death of BDNF-dependent cranial sensory neurons, particularly from nodose, petrosal and vestibular ganglia (Hellard et al., 2004). BAX translocates to the mitochondria and induces mitochondria outer membrane permeabilization (MOMP; Kalkavan and Green, 2018); in many circumstances MOMP provokes the release of the proapoptotic proteins SMAC and cytochrome c, engaging in the recruitment and activation of executioner caspases. However, since cleaved caspase-3 levels did not rise, and caspase blockers did not slow neuronal loss, in DRG sensory neurons deprived of BDNF, BAX must facilitate cell loss through a caspase-independent mechanism in this setting. BAX-dependent and caspase-independent cell death typically involves mitochondrial potential loss and failure (Deshmukh et al., 2000; Chang and Johnson, 2002; Chang et al., 2003; LangRollin et al., 2003), with BAX-mediated MOMP inducing an increase of mitochondrial ROS production (Jiang et al., 2008; Garcia-Perez et al., 2012). In some circumstances, BAXmediated MOMP and ROS production can trigger the formation of the mitochondria permeability transition pore which has been implicated in several forms of neuronal death (Lamarche et al., 2013).

A recent review by Fricker et al. (2018) proposed the existence of at least twelve different cell death pathways, highlighting the diversity and complexity of cellular death mechanisms (Fricker et al., 2018). Here, we examined prodegenerative pathways such as necroptosis and autophagy and mechanisms such as protein translation and NAD + metabolism. Our results showed that several of these pathways impinge on the degenerative process induced by NGF deprivation but blockade of necroptosis, autophagy or translation nor NAD+ supplementation rescued degeneration evoked by BDNF withdrawal.

In conclusion, we have provided the first in depth characterization of the mechanisms that mediate degeneration of BDNF-dependent DRG sensory neurons on trophic factor withdrawal. We show that the pathways regulating the degeneration of BDNF-dependent DRG sensory neurons requires BAX and ROS but are Trk and caspase independent and distinct from those invoked on NGF withdrawal.

\section{References}

Acheson A, Barker PA, Alderson RF, Miller FD, Murphy RA (1991) Detection of brain-derived neurotrophic factor-like activity in fibroblasts and Schwann cells: inhibition by antibodies to NGF. Neuron 7:265-275.

Bamji SX, Majdan M, Pozniak CD, Belliveau DJ, Aloyz R, Kohn J, Causing CG, Miller FD (1998) The p75 neurotrophin receptor mediates neuronal apoptosis and is essential for naturally occurring sympathetic neuron death. J Cell Biol 140:911-923.

Barde YA (1989) Trophic factors and neuronal survival. Neuron 2:1525-1534.

Barker PA, Shooter EM (1994) Disruption of NGF binding to the low affinity neurotrophin receptor p75LNTR reduces NGF binding to TrkA on PC12 cells. Neuron 13:203-215.

Borasio GD, John J, Wittinghofer A, Barde YA, Sendtner M, Heumann R (1989) ras p21 protein promotes survival and fiber outgrowth of cultured embryonic neurons. Neuron 2:1087-1096.

Burek MJ, Oppenheim RW (1996) Programmed cell death in the developing nervous system. Brain Pathol 6:427-446.

Buss RR, Sun W, Oppenheim RW (2006) Adaptive roles of programmed cell death during nervous system development. Annu Rev Neurosci 29:1-35.

Carter BD, Zirrgiebel U, Barde YA (1995) Differential regulation of p21ras activation in neurons by nerve growth factor and brain-derived neurotrophic factor. J Biol Chem 270:21751-21757.

Chang LK, Johnson EM Jr (2002) Cyclosporin A inhibits caspase-independent death of NGF-deprived sympathetic neurons: a potential role for mitochondrial permeability transition. J Cell Biol 157:771-781.

Chang LK, Schmidt RE, Johnson EM Jr (2003) Alternating metabolic pathways in NGF-deprived sympathetic neurons affect caspaseindependent death. J Cell Biol 162:245-256.

Deppmann CD, Mihalas S, Sharma N, Lonze BE, Niebur E, Ginty DD (2008) A model for neuronal competition during development. Science 320:369-373.

Deshmukh M, Kuida K, Johnson EM Jr (2000) Caspase inhibition extends the commitment to neuronal death beyond cytochrome c release to the point of mitochondrial depolarization. J Cell Biol 150:131-143.

Ernfors P, Lee KF, Jaenisch R (1994a) Mice lacking brain-derived neurotrophic factor develop with sensory deficits. Nature 368: 147-150.

Ernfors P, Lee KF, Kucera J, Jaenisch R (1994b) Lack of neurotrophin-3 leads to deficiencies in the peripheral nervous system and loss of limb proprioceptive afferents. Cell 77:503-512.

Ernsberger U (2009) Role of neurotrophin signalling in the differentiation of neurons from dorsal root ganglia and sympathetic ganglia. Cell Tissue Res 336:349-384. 
Fariñas I, Wilkinson GA, Backus C, Reichardt LF, Patapoutian A (1998) Characterization of neurotrophin and Trk receptor functions in developing sensory ganglia: direct NT-3 activation of TrkB neurons in vivo. Neuron 21:325-334.

Feinberg K, Kolaj A, Wu C, Grinshtein N, Krieger JR, Moran MF, Rubin L, Miller FD, Kaplan DR (2017) A neuroprotective agent that inactivates prodegenerative TrkA and preserves mitochondria. $\mathrm{J}$ Cell Biol 216:3655-3675.

Fischer LR, Glass JD (2007) Axonal degeneration in motor neuron disease. Neurodegener Dis 4:431-442.

Fricker M, Tolkovsky AM, Borutaite V, Coleman M, Brown GC (2018) Neuronal cell death. Physiol Rev 98:813-880.

Garcia-Perez C, Roy SS, Naghdi S, Lin X, Davies E, Hajnóczky G (2012) Bid-induced mitochondrial membrane permeabilization waves propagated by local reactive oxygen species (ROS) signaling. Proc Natl Acad Sci USA 109:4497-4502.

Geden MJ, Romero S, Deshmukh M (2019) Apoptosis versus axon pruning: molecular intersection of two distinct pathways for axon degeneration. Neurosci Res 139:3-8.

Glebova N, Ginty DD (2005) Growth and survival signals controlling sympathetic nervous system development. Annu Rev Neurosci 28:191-222.

Haapasalo A, Sipola I, Larsson K, Akerman K, Stoilov P, Stamm S, Wong G, Castren E (2002) Regulation of TRKB surface expression by brain-derived neurotrophic factor and truncated TRKB isoforms. J Biol Chem 277:43160-43167.

Hellard D, Brosenitsch T, Fritzsch B, Katz DM (2004) Cranial sensory neuron development in the absence of brain-derived neurotrophic factor in BDNF/Bax double null mice. Dev Biol 275:34-43.

Huber K, Kuehnel F, Wyatt S, Davies AM (2000) TrkB expression and early sensory neuron survival are independent of endogenous BDNF. J Neurosci Res 59:372-378.

Jiang J, Huang Z, Zhao Q, Feng W, Belikova N, Kagan VE (2008) Interplay between bax, reactive oxygen species production, and cardiolipin oxidation during apoptosis. Biochem Biophys Res Commun 368:145-150.

Johnson JE, Barde YA, Schwab M, Thoenen H (1986) Brain-derived neurotrophic factor supports the survival of cultured rat retinal ganglion cells. J Neurosci 6:3031-3038.

Johnstone AD, Hallett RM, De Léon A, Carturan B, Gibon J, Barker PA (2018) A novel method for quantifying axon degeneration. PLoS One 13:e0199570.

Johnstone AD, De Léon A, Unsain N, Gibon J, Barker PA (2019) Developmental axon degeneration requires TRPV1-dependent $\mathrm{Ca}$ (2+) influx. eNeuro 6:ENEURO.0019-19.2019.

Kalcheim C, Barde YA, Thoenen H, Le Douarin NM (1987) In vivo effect of brain-derived neurotrophic factor on the survival of developing dorsal root ganglion cells. EMBO J 6:2871-2873.

Kalkavan H, Green DR (2018) MOMP, cell suicide as a BCL-2 family business. Cell Death Differ 25:46-55.

Kanaan NM, Pigino GF, Brady S, Lazarov O, Binder LI, Morfini GA (2013) Axonal degeneration in Alzheimer's disease: when signaling abnormalities meet the axonal transport system. Exp Neurol 246:44-53.

Kirkland R, Franklin JL (2001) Evidence for redox regulation of cytochrome $\mathrm{C}$ release during programmed neuronal death: antioxidant effects of protein synthesis and caspase inhibition. J Neurosci 21:1949-1963.

Kirkland R, Franklin JL (2003) Bax, reactive oxygen, and cytochrome c release in neuronal apoptosis. Antioxid Redox Signal 5:589-596.

Kirkland R, Franklin JL (2007) Bax affects production of reactive oxygen by the mitochondria of non-apoptotic neurons. Exp Neurol 204:458-461.

Kirkland R, Windelborn J, Kasprzak J, Franklin JM (2002) A Bax-induced pro-oxidant state is critical for cytochrome $\mathrm{c}$ release during programmed neuronal death. J Neurosci 22:6480-6490.

Kirkland R, Saavedra GM, Cummings BS, Franklin JL (2010) Bax regulates production of superoxide in both apoptotic and nonapoptotic neurons: role of caspases. J Neurosci 30:16114-16127.
Kirstein M, Fariñas I (2002) Sensing life: regulation of sensory neuron survival by neurotrophins. Cell Mol Life Sci 59:1787-1802.

Knudson CM, Tung KS, Tourtellotte WG, Brown GA, Korsmeyer SJ (1995) Bax-deficient mice with lymphoid hyperplasia and male germ cell death. Science 270:96-99.

Lallemend F, Ernfors P (2012) Molecular interactions underlying the specification of sensory neurons. Trends Neurosci 35:373-381.

Lamarche F, Carcenac C, Gonthier B, Cottet-Rousselle C, Chauvin C, Barret L, Leverve X, Savasta M, Fontaine E (2013) Mitochondrial permeability transition pore inhibitors prevent ethanol-induced neuronal death in mice. Chem Res Toxicol 26:78-88.

Lang-Rollin I, Rideout HJ, Noticewala M, Stefanis L (2003) Mechanisms of caspase-independent neuronal death: energy depletion and free radical generation. J Neurosci 23:11015-11025.

Lee KF, Li E, Huber LJ, Landis S, Sharpe AH, Chao MV, Jaenisch R (1992) Targeted mutation of the gene encoding the low affinity NGF receptor $p 75$ leads to deficits in the peripheral sensory nervous system. Cell 69:737-749.

Levi-Montalcini R, Booker B (1960) Destruction of the sympathetic ganglia in mammals by an antiserum to a nerve-growth protein. Proc Natl Acad Sci USA 46:384-391.

Liebl DJ, Tessarollo L, Palko ME, Parada LF (1997) Absence of sensory neurons before target innervation in brain-derived neurotrophic factor-, neurotrophin 3-, and TrkC-deficient embryonic mice. J Neurosci 17:9113-9121.

Mehlen P, Bredesen D (2004) The dependence receptor hypothesis. Apoptosis 9:37-49.

Nikoletopoulou V, Lickert H, Frade JM, Rencurel C, Giallonardo P, Zhang L, Bibel M, Barde YA (2010) Neurotrophin receptors TrkA and TrkC cause neuronal death whereas TrkB does not. Nature 467:59-63.

Patel TD, Jackman A, Rice FL, Kucera J, Snider WD (2000) Development of sensory neurons in the absence of NGF/TrkA signaling in vivo. Neuron 25:345-357.

Roux P, Barker PA (2002) Neurotrophin signaling through the p75 neurotrophin receptor. Prog Neurobiol 67:203-233.

Saxena S, Caroni P (2007) Mechanisms of axon degeneration: from development to disease. Prog Neurobiol 83:174-191.

Schoenmann Z, Assa-Kunik E, Tiomny S, Minis A, Haklai-Topper L, Arama E, Yaron A (2010) Axonal degeneration is regulated by the apoptotic machinery or a NAD+-sensitive pathway in insects and mammals. J Neurosci 30:6375-6386.

Schuldiner O, Yaron A (2015) Mechanisms of developmental neurite pruning. Cell Mol Life Sci 72:101-119.

Shacham-Silverberg V, Sar Shalom H, Goldner R, Golan-Vaishenker Y, Gurwicz N, Gokhman I, Yaron A (2018) Phosphatidylserine is a marker for axonal debris engulfment but its exposure can be decoupled from degeneration. Cell Death Dis 9:1116.

Simon DJ, Weimer RM, Mclaughlin T, Kallop D, Stanger K, Yang J, O'leary D, Hannoush RN, Tessier-Lavigne M (2012) A caspase cascade regulating developmental axon degeneration. J Neurosci 32:17540-17553.

Singh KK, Park KJ, Hong EJ, Kramer BM, Greenberg M, Kaplan DR, Miller FD (2008) Developmental axon pruning mediated by BDNFp75NTR-dependent axon degeneration. Nat Neurosci 11:649658.

Sommerfeld MT, Schweigreiter R, Barde YA, Hoppe E (2000) Downregulation of the neurotrophin receptor TrkB following ligand binding. Evidence for an involvement of the proteasome and differential regulation of TrkA and TrkB. J Biol Chem 275:8982-8990.

Tait SW, Green DR (2010) Mitochondria and cell death: outer membrane permeabilization and beyond. Nat Rev Mol Cell Biol 11:621632.

Tauszig-Delamasure S, Yu LY, Cabrera JR, Bouzas-Rodriguez J, Mermet-Bouvier C, Guix C, Bordeaux MC, Arumäe U, Mehlen P (2007) The TrkC receptor induces apoptosis when the dependence receptor notion meets the neurotrophin paradigm. Proc Natl Acad Sci USA 104:13361-13366.

Tessarollo L, Tsoulfas P, Donovan MJ, Palko ME, Blair-Flynn J, Hempstead B, Parada L (1997) Targeted deletion of all isoforms of 
the trkC gene suggests the use of alternate receptors by its ligand neurotrophin-3 in neuronal development and implicates trkC in normal cardiogenesis. Proc Natl Acad Sci USA 94:14776-14781.

Unsain N, Higgins JM, Parker KN, Johnstone AD, Barker P (2013) XIAP regulates caspase activity in degenerating axons. Cell Rep 4:751-763.

Unsain N, Heard K, Higgins JM, Barker PA (2014) Production and isolation of axons from sensory neurons for biochemical analysis using porous filters. J Vis $\operatorname{Exp}(89): 51795$.

Valdés-Sánchez T, Kirstein M, Pérez-Villalba A, Vega JA, Fariñas I (2010) BDNF is essentially required for the early postnatal survival of nociceptors. Dev Biol 339:465-476.
Vickers JC, King A, Woodhouse A, Kirkcaldie MT, Staal J, Mccormack GH, Blizzard C, Musgrove R, Mitew S, Liu Y, Chuckowree J, Bibari O, Dickson TC (2009) Axonopathy and cytoskeletal disruption in degenerative diseases of the central nervous system. Brain Res Bull 80:217-223.

Wakatsuki S, Araki T (2017) Specific phospholipid scramblases are involved in exposure of phosphatidylserine, an "eat-me" signal for phagocytes, on degenerating axons. Commun Integr Biol 10: e1296615.

Wilson C, Muñoz-Palma E, González-Billault C (2018) From birth to death: a role for reactive oxygen species in neuronal development. Semin Cell Dev Biol 80:43-49. 